Universidade de São Paulo

Faculdade de Odontologia de Ribeirão Preto

Josilaine Amaral Pimenta

Avaliação do efeito de diferentes agentes quelantes e desmineralizantes sobre a microdureza da dentina radicular 
Josilaine Amaral Pimenta

\section{Avaliação do efeito de diferentes agentes quelantes e desmineralizantes sobre a microdureza da dentina radicular}

Dissertação apresentada à Faculdade de Odontologia de Ribeirão Preto da Universidade de São Paulo para obtenção do Grau de Mestre em Odontologia, área de concentração Endodontia.

Orientador: Prof. Dr. Antônio Miranda da Cruz Filho 
Autorizo a reprodução e divulgação total ou parcial deste trabalho, por qualquer meio convencional ou eletrônico, para fins de estudo e pesquisa, desde que citada a fonte.

Pimenta, Josilaine Amaral

Avaliação do efeito de diferentes agentes quelante $e$ desmineralizantes sobre a microdureza da dentina radicular. Ribeirão Preto, 2011.

51 p. : il. ; $30 \mathrm{~cm}$

Dissertação de Mestrado, apresentada à Faculdade de Odontologia de Ribeirão Preto/USP, Departamento de Odontologia Restauradora Endodontia.

Orientador: Cruz Filho, Antônio Miranda

1. Microdureza. 2. Agentes Quelantes. 3. Quitosana. 4. EDTA. 5. Ácido Cítrico. 

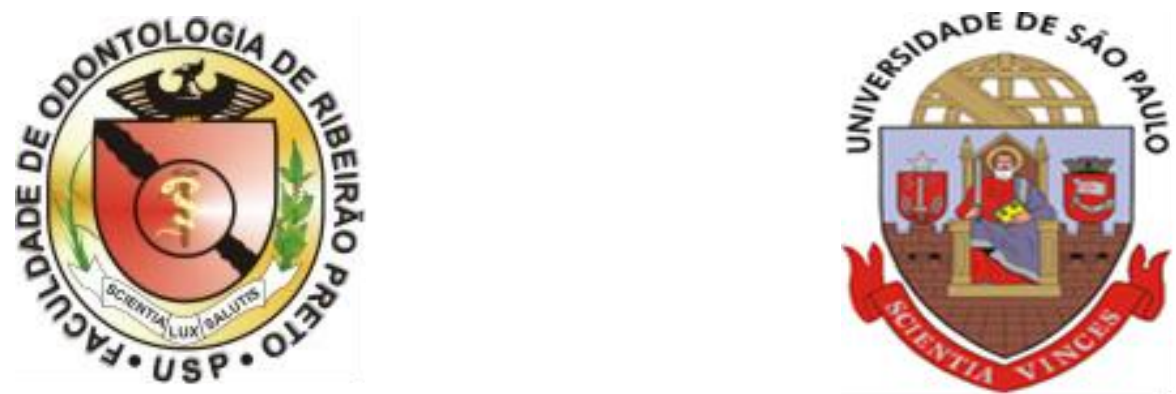

Este trabalho foi realizado no Laboratório de Pesquisa em Endodontia e no Laboratório de Pesquisa do Departamento de Odontologia Restauradora da Faculdade de Odontologia de Ribeirão Preto da Universidade de São Paulo. 
Pimenta, J. A. Avaliação do efeito de diferentes agentes quelantes e desmineralizantes sobre a microdureza da dentina radicular. Dissertação de Mestrado em Odontologia Restauradora: Endodontia. Faculdade de Odontologia de Ribeirão Preto, Universidade de São Paulo.

Aprovado em:

Banca Examinadora

1)Prof.(a) Dr.(a)

Instituição: Assinatura:

2)Prof.(a) Dr.(a)

Instituição: Assinatura:

3)Prof.(a) Dr.(a)

Instituição: Assinatura: 


\section{DEDICATÓRIA}

Aos meus pais, Sebastião e Onofra, pelo apoio constante, pela dedicação, educação e exemplos de dignidade e honra durante toda minha vida.

Ao meu esposo Roberto, pelo carinho, apoio incondicional e incentivo. Que soube compartilhar as dificuldades desta caminhada e acreditou em meus sonhos, até quando eu mesma duvidava. O meu sucesso é seu também.

Ao pequeno Felipe, filho querido, que coloriu meus dias. A você que eu amo a cada segundo. Obrigada por colocar um sorriso no meu rosto em qualquer dificuldade, por existir e fazer os meus sonhos realidade. Mamãe te ama. 


\section{AGRADECIMENTOS}

A Deus, que se faz presente a todo o momento em minha vida. Obrigada por minha existência.

Ao meu orientador Prof. Dr. Antonio Miranda da Cruz Filho, agradeço pela orientação, paciência e compreensão. Obrigada por me ajudar a vencer mais esta etapa na minha vida profissional. Com todo seu conhecimento e capacidade, soube mostrarme que é possível alcançar nossos objetivos, seja pessoal ou profissional.

Ao Prof. Dr. Jesus Djalma Pécora, pela oportunidade, cooperação e incentivo.

Ao Prof. Dr. Manoel Damião de Sousa Neto, pela dedicação e conhecimentos científicos transmitidos. 
Aos Professores Dr. Luiz Pascoal Vansan, Dr. Ricardo Gariba Silva, Dr. Ricardo Novak Savioli e, em especial, ao Prof. José Antônio Brufato Ferraz pela amizade, exemplo profissional e pela enorme contribuição para meu aprendizado em Endodontia.

Aos meus colegas de mestrado, Juliane Nhata, Kleber Campioni Dias, Luciana Santello, Marcus Vinicius de Melo, Rayana Bigheti e Samuel Henrique Câmara De Bem, juntos na busca pelo mesmo objetivo, pela amizade, convivência e colaboração.

Ao Técnico do Laboratório de Endodontia da FORP-USP, Reginaldo Santana, pelo apoio, carinho e amizade.

À Técnica do Laboratório de Endodontia da FORP-USP, Luiza Godoi Pitol, pela gentileza e carinho a todo instante.

Ao secretário de Departamento de Odontologia Restauradora FORP-USP, Carlos Feitosa dos Santos, pela disponibilidade a todo o momento, amizade e incentivo.

Às funcionárias do Departamento de Odontologia Restauradora FORP-USP, Maria Amália Viesti e Maria Isabel, pelo profissionalismo, simpatia e auxilio.

Às funcionárias da seção de Pós-Graduação, Isabel Cristina Sola e Regiane Saciolloto, pela disponibilidade e apoio a todo o momento. 
À CAPES, pela bolsa de estudos outorgada.

À Faculdade de Odontologia de Ribeirão Preto - Universidade de São Paulo, pela oportunidade de formação profissional e por ter me acolhido tão bem.

Aos meus familiares, que sempre torceram pelo meu sucesso.

Meus sinceros agradecimentos! 


\section{RESUMO}

Pimenta, J. A. Avaliação do efeito de diferentes agentes quelantes e desmineralizantes sobre a microdureza da dentina radicular. 2011. 51 p. Dissertação de Mestrado - Faculdade de Odontologia de Ribeirão Preto, Universidade de São Paulo, Ribeirão Preto, 2011.

O presente estudo teve como objetivo avaliar a ação das soluções de quitosana, EDTA e ácido cítrico sobre a microdureza da dentina radicular. Utilizaram-se 10 incisivos centrais superiores humanos, os quais tiveram suas coroas seccionadas transversalmente e desprezadas. As raízes foram incluídas em resina acrílica de rápida polimerização e o bloco formado raiz/resina adaptado a máquina de corte. Desprezou-se o primeiro corte transversal da porção cervical e dividiu-se o segundo, em quatro quadrantes. Cada quarto foi destinado à confecção do corpo de prova obtendo-se 4 espécimes para cada raiz, um para cada solução (n=10): G1- EDTA 15\%; G2- ácido cítrico; G3- quitosana $0,2 \%$ e G4- controle. Os espécimes receberam $50 \mu \mathrm{L}$ da solução por 5 minutos, sendo em seguida, lavados com água deionizada. Utilizou-se um microdurômetro (dureza Knoop) com carga de $10 \mathrm{~g}$ durante 15 segundos. Os resultados mostraram que todas as soluções avaliadas apresentaram capacidade de reduzir a microdureza da dentina radicular de forma semelhante entre si e estatisticamente diferente a do grupo controle ( $\mathrm{p}<0,01)$. Concluiu-se as soluções de quitosana 0,2\%, EDTA $15 \%$ e ácido cítrico $10 \%$ apresentam efeito semelhante na redução da microdureza dentinária.

Descritores: 1.Microdureza; 2. agentes quelantes; 3. Quitosana; 4. EDTA; 5. Ácido Cítrico. 


\section{ABSTRACT}

Pimenta, J.A. Evaluation of the effect of different chelating agents and demineralizing on the microhardness of root dentin. 2011. 51 p. Dissertação de Mestrado - Faculdade de Odontologia de Ribeirão Preto, Universidade de São Paulo, Ribeirão Preto, 2011.

The aim of this study was to evaluate the action of solutions: chitosan, EDTA and citric acid on the microhardness of the root dentin. There were used 10 human maxillary central incisors which ones had their crown cross-sectioned and discarded. The roots were embedded in acrylic resin of rapid polymerization and the block formed root/resin suitable by cutting machine. Neglecting the first cross-section of the cervical portion and the second was divided in four quadrants. Each quarter was destined to the confection of the specimen and it was got 4 specimen to each root, one for each solution $(\mathrm{n}=10)$ : G1- EDTA 15\%; G2- citric acid;G3- chitosan 0,2 \% and G4- control. The specimen received $50 \mu \mathrm{L}$ of the solution for 5 minutes, and following up they were washed by deionized water. It was used a microhardness (Knoop hardness) with a load of $10 \mathrm{~g}$ during 15 seconds. The results showed that all the solutions evaluated presented a capacity to reduce the microhardness of the root dentin in a similar way between them, and statically differ from the control group $(\mathrm{p}<0,01)$. It was concluded that chitosan $0,2 \%$ EDTA $15 \%$ and the citric acid $10 \%$ presented a similar effect in the reduction of the dentin microhardness.

Descriptors: 1.Microhardness; 2. Chelating agents; 3. Chitosan; 4. EDTA; 5. Citric Acid. 


\section{SUMÁRIO}

RESUMO

ABSTRACT

INTRODUÇÃ

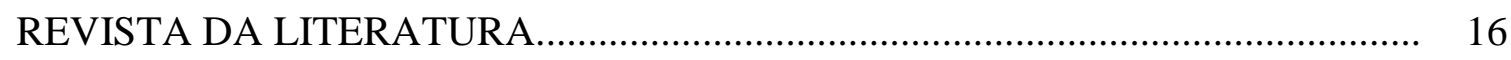

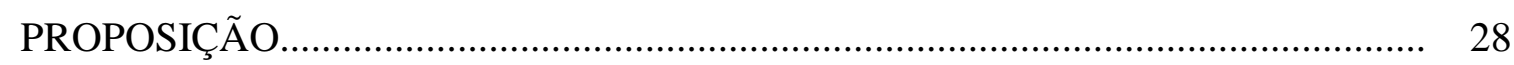

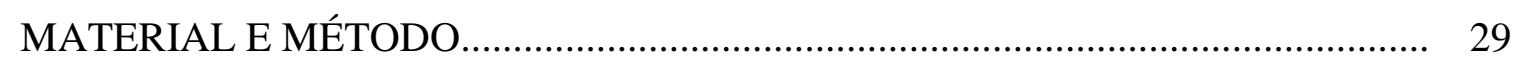

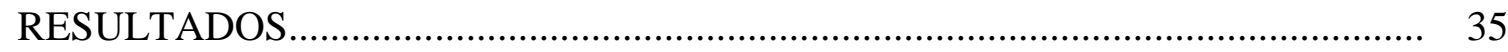

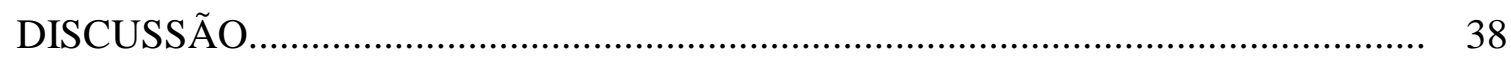

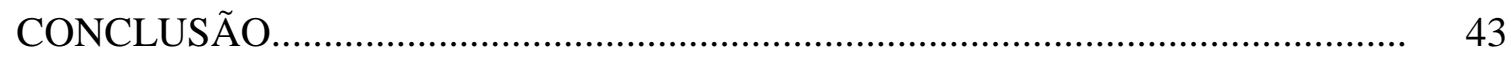

REFERÊNCIAS BIBLIOGRÁFICAS............................................................ 44

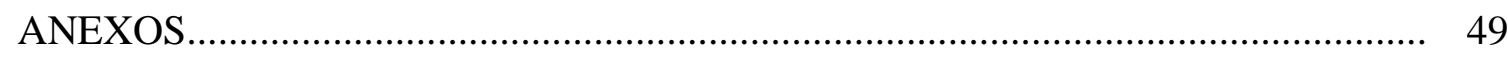




\section{INTRODUÇÃO}

A limpeza do sistema de canais radiculares durante o preparo biomecânico ocorre por meio da ação mecânica dos instrumentos endodônticos que, associada às propriedades físico-químicas das soluções irrigadoras e dos medicamentos, tem por objetivo eliminar agentes agressores e irritantes como os microorganismos, seus produtos e restos de tecido pulpar, degradados ou não (HÜSLMANN et al., 2003).

A ação dos instrumentos endodônticos, seja por meio da técnica de instrumentação mecanizada ou manual, ao mesmo tempo em que contribui para a obtenção da limpeza e santificação favorece a deposição de microrganismos e restos de tecidos dentinários e pulpares junto às paredes do canal radicular promovendo a formação da smear layer.

Embora a influência da smear layer sobre a taxa de sucesso do tratamento endodôntico não tenha sido definitivamente determinada, é importante salientar que a indicação de diferentes soluções é, frequentemente, sugerida para remover ou impedir a formação desta camada. Dentre as soluções estudadas para esta finalidade destaca-se o ácido cítrico e EDTA (De-DEUS et al., 2006; SPANÓ et al., 2009). 
O efeito quelante dessas soluções ocorre concomitantemente e indistintamente sobre a smear layer e dentina radicular, com consequente exposição de colágeno, e redução da microdureza dentinária (SLUTZKY-GOLDBERG et al., 2004; De-DEUS et al., 2006; De-DEUS et al., 2008c).

A quelação é um processo físico-químico que promove a absorção de íons metálicos. No caso específico da dentina, a solução reage com os íons cálcio dos cristais de hidroxiapatita alterando a microestrutura da dentina e mudando a relação cálcio/fósforo $(\mathrm{Ca} / \mathrm{P})$. Esta mudança interfere na composição orgânica e inorgânica do tecido com conseqüente alteração da permeabilidade, solubilidade e microdureza dentinária (PANIGHI; G’SELL, 1992; De-DEUS et al., 2006).

Apesar da aparente fragilidade do elemento dental causada pela redução da microdureza, o efeito redutor tem sido vantajoso no preparo de canais radiculares, principalmente, dos atrésicos. A dentina amolecida é facilmente excisada favorecendo a ação dos instrumentos endodônticos e agilizando a fase de preparo biomecânico.

A camada de pré-dentina a ser removida durante a instrumentação do canal radicular, originariamente, apresenta-se menos dura que a dentina subjacente facilitando ainda mais a ação do agente quelante. Há uma relação inversa entre a microdureza da dentina e a densidade tubular. A porção dentinária mais próxima à polpa dental apresenta menor dureza, devido a maior densidade tubular e maior diâmetro dos túbulos dentinários nessa região (PASHLEY et al., 1985).

A primeira substância quelante empregada na odontologia foi o ácido etileno diamino tetra acético (EDTA), proposto por Nygaard-Østby, em 1957, para facilitar a instrumentação de canais atrésicos.

Ao longo do tempo inúmeras soluções quelantes e desmineralizantes foram propostas e estudadas, no sentido de avaliar a capacidade de descalcificação e o efeito redutor sobre a microdureza: EDTA (CRUZ-FILHO et al., 1996; FAIRBANKS et al., 1997; SALEH; ETTMAN, 1999; CRUZ-FILHO et al., 2001; ARI et al., 2004; QING et al., 2006; De-DEUS et al., 2006), EDTAC, EDTA-T (FAIRBANKS et al., 1997; CRUZ-FILHO et al., 2001, De-DEUS et al., 2008b), EGTA (CRUZ-FILHO et al., 2001; CRUZ-FILHO et al., 2002; SOUSA; SILVA, 2005; MARQUES et al., 2006; SAYIN et al., 2007), CDTA (CRUZ-FILHO et al., 2001; SOUSA; SILVA, 2005; MARQUES et al., 2006), ácido cítrico (MACHADO-SILVEIRO et al., 2004; ELDENIZ et al., 2005; De-DEUS et al., 2006; SAYIN et al., 2007; REIS et al., 2008), peróxido de hidrogênio (ARI et al., 2004), hipoclorito de sódio 6\% (SLUTZKY- 
GOLDBERG et al., 2004), citrato de sódio (MACHADO-SILVEIRO et al., 2004), ácido fosfórico (PÉREZ-HEREDIA et al., 2006, PÉREZ-HEREDIA et al., 2008), MTAD (De-DEUS et al., 2007), Clorexidina (OLIVEIRA et al., 2007), ácido etidrônico (De-DEUS et al., 2008c; LOTTANTI et al., 2009), Smear Clear (De-DEUS et al., 2008b).

Dentre as soluções utilizadas para reduzir a microdureza dentinária, o EDTA e suas associações é o mais, rotineiramente, utilizado.

Fairbanks et al. (1997) estudaram a capacidade quelante do EDTA, EDTAC e EDTA-T e observaram que a solução de EDTAC foi a mais eficiente na redução da microdureza da dentina.

A solução de EDTAC inicia o processo de quelação assim que entra e contato com o tecido, e a microdureza é reduzida em função do tempo de aplicação. Assim, quanto maior o tempo de contato da solução com a dentina, maior a redução da microdureza (CRUZ-FILHO et al., 1996).

A eficiência dos agentes quelantes depende de muitos fatores, tais como o tempo de aplicação, o pH, a concentração da solução e a quantidade de solução disponível (ÇALT e SERPER, 2002; HÜLSMANN et al., 2003 e MARQUES et al., 2006).

$\mathrm{O}$ ácido cítrico, um ácido orgânico fraco, é utilizado para a remoção da smear layer e sua eficiência tem sido estudada e muitas vezes comparada à do EDTA (SPANÓ et al., 2009).

Cruz-Filho et al. (2011) verificaram que as soluções de EDTA e ácido cítrico comportaram-se de maneira semelhante em relação à redução da microdureza da dentina que recobre o longo eixo do canal radicular. Porém, o trabalho de De-DEUS et al. (2008a) revela que a capacidade do ácido cítrico em desmineralizar a dentina é superior a do EDTA, além de apresentar menor citotoxicidade (ANDO, 1985).

A preocupação em minimizar o efeito tóxico aos tecidos periapicais, por meio do uso de soluções mais biocompatíveis que o EDTA, como os ácidos fracos despertou a curiosidade da comunidade científica (HAZNEDAROGLU, 2003; SPANÓ et al., 2009; PRADO et al., 2011).

A quitosana é um polissacarídeo natural, o qual tem atraído grande atenção dos pesquisadores da área odontológica devido às suas propriedades de biocompatibilidade, biodegradabilidade, bioadesão e atoxidade diante do organismo humano (SENEL et al., 2000; AKNCBAY et al., 2007). Essa substância é aviada por desacetilação da quitina, a qual é obtida a partir de cascas de caranguejo e camarão (URAGAMI et al., 2003). 
A quitosana possui alta capacidade quelante por vários íons metálicos (incluindo $\mathrm{Ni}^{2+}, \mathrm{Zn}^{2+}, \mathrm{Co}^{2+,} \mathrm{Fe}^{2+}, \mathrm{Mg}^{2+}$ e $\mathrm{Cu}^{2+}$ ) em condições ácidas, e tem sido amplamente aplicado para remoção ou recuperação dos íons metálicos em diferentes setores da indústria (KURITA, 1998).

Diante da comprovada propriedade quelante e biocompatibilidade da quitosana é cabível a realização de estudos com intuito de dirimir dúvidas e ampliar o conhecimento a respeito da sua ação sobre a microdureza dentinária, comparando-a, principalmente, às soluções de EDTA e ácido cítrico, amplamente utilizadas na odontologia. 


\section{REVISTA DA LITERATURA}

Nygaard-Østby (1957) propôs o uso do ácido etilenodiaminotetraacético (EDTA) para a instrumentação dos canais radiculares. O EDTA em pH 7,3 é biologicamente compatível com tecidos pulpares e periapicais. Assim preconizou-se o seu uso em substituição aos ácidos inorgânicos fortes, até então utilizados.

Pashley et al. (1985) analisaram a correlação da microdureza da dentina com a densidade dos túbulos dentinários. Os autores utilizaram cortes transversais de terceiros molares corados no sentido da câmara pulpar à junção dentina-cemento. Os espécimes foram levados ao microdurômetro e as áreas mensuradas foram fotografadas para quantificação dos canalículos dentinários. Concluíram que quanto maior o número de canalículos na região, menor a microdureza dentinária.

Panighi; G’sell (1992) pesquisaram a influência da concentração de cálcio na permeabilidade dentinária por meio de adesivo Scotchbond ${ }^{\circledR}$. Cortes transversais da raiz de molares foram incluídos em resina e polidos. Os espécimes receberam duas gotas de solução de ácido cítrico $50 \%$ por 30 segundos para remoção da smear layer e na sequência foram lavados com água pelo mesmo tempo. Analisaram-se a microdureza dentinária, concentração de cálcio e fósforo e a capacidade de umectação do adesivo na 
superfície dentinária. Os pesquisadores observaram que as superfícies de dentina com maior grau de mineralização exibem maiores valores de microdureza e são também mais umedecidas pelo adesivo.

Burrow et al. (1994) investigaram a influência da idade do paciente e da profundidade da camada de dentina na resistência à tração dos sistemas adesivos: Scotchbond Multi-purpose ${ }$, Superbond D-liner® e Liner Bond II®. Molares humanos foram separados em dois grupos a partir da idade: 1- pacientes com menos de 30 anos e; 2- com mais de 50 anos. Discos de dentina foram obtidos da região localizada logo abaixo ao esmalte (camada superficial), e próxima aos cornos pulpares (camada profunda). Os autores concluíram que a idade do paciente e profundidade da camada de dentina podem não ter grande influência na resistência à tração dos adesivos, mas a presença de maior número de túbulos dentinários próximos à polpa oferece menor resistência nessa região.

Salama; Abdelmegid (1994) realizaram um estudo piloto, in vitro, analisando a capacidade do ácido cítrico $6 \%$ e do peróxido de hidrogênio em remover a smear layer do canal radicular. Os resultados mostraram que o ácido cítrico foi bastante eficiente, tanto na remoção da smear layer, quanto da smear plug, sendo superior ao peróxido de hidrogênio.

Cruz-Filho et al. (1996) analisaram o efeito do EDTAC em diferentes tempos de aplicação na microdureza dentinária de incisivos centrais superiores humanos. Concluíram que a redução da microdureza faz-se sentir no primeiro minuto de aplicação da solução, e que a microdureza da dentina é diminuída em função do tempo de aplicação do agente quelante.

Fairbanks et al. (1997) avaliaram a capacidade quelante das soluções de EDTA, EDTAC e EDTA-T na dentina radicular. As soluções testadas foram aplicadas durante 5 minutos, sendo mensurada a dureza Vickers após o tratamento. A análise estatística evidenciou que todas as soluções foram capazes de reduzir a microdureza da dentina. $\mathrm{O}$ EDTA e EDTA-T agiram de modo semelhante entre si e foram menos efetivos que a solução de EDTAC.

Kurita (1998) estudou as propriedades químicas da quitina e quitosana. O autor relatou que por meio da desacetilação da quitina obtém-se a quitosana, a qual é um polissacarídeo natural com alta capacidade quelante. Esta substância apresenta ainda, propriedades antimicrobianas, biocompatibilidade, é biodegradável além de, estar sendo amplamente aplicada na remoção de íons metálicos em diferentes setores da indústria. 
Saleh; Ettman (1999) analisaram o efeito do peróxido de hidrogênio $\left(\mathrm{H}_{2} \mathrm{O}_{2}\right)$ e do EDTA na microdureza da dentina humana. Dezoito raízes de incisivos superiores foram instrumentadas e seccionadas transversalmente nos terços cervical, médio e apical. Os terços foram distribuídos em dois grupos. No primeiro, depositou-se $\mathrm{H}_{2} \mathrm{O}_{2} 3 \%$ e $\mathrm{NaOCl}$ $5 \%$ no lúmen do canal radicular, e no segundo, utilizou-se EDTA 17\%. Posteriormente mediu-se a microdureza Knoop nas distâncias de $500 \mu \mathrm{m}$ e $1000 \mu \mathrm{m}$ da luz do canal radicular. Os pesquisadores verificaram que ambas as soluções reduziram a microdureza dentinária, no entanto, o EDTA foi significantemente mais eficiente.

Em 2000, o trabalho de Senel et al. evidenciou que a quitosana é um biomaterial de grande interesse à área odontológica, em função das suas propriedades de biocompatibilidade, biodegradabilidade, bioadesão e atoxidade diante do organismo humano.

Chatelet et al. (2001) investigaram a função do grau de acetilação em propriedades biológicas de películas de quitosana. Observaram que a quitosana é biocompativel e atóxica às células humanas e concluíram que o grau de acetilação desempenha um papel fundamental na adesão e proliferação celular, mas não altera a citocompatibilidade da substância.

Cruz-Filho et al. (2001) pesquisaram a ação do EDTAC 15\%, CDTA $1 \%$ e EGTA $1 \%$ na microdureza da dentina radicular. Cinco raízes de incisivos centrais superiores foram cortadas transversalmente aproveitando-se apenas o segundo corte da região cervical, o qual foi dividido em quatro partes. Cada quadrante foi submetido à ação de uma solução quelante. Água destilada e deionizada serviu como controle. Aplicaram-se sobre o corpo de prova $50 \mu \mathrm{L}$ da solução a ser testada por um período de 5 minutos. A microdureza foi avaliada por meio de um aparelho de dureza Vickers com carga de $50 \mathrm{~g}$ durante 15 segundos. Os resultados mostraram que as 3 soluções avaliadas reduziram a microdureza dentinária de forma semelhante entre si.

Cruz-Filho et al. (2002) avaliaram o efeito da solução de EGTA em diferentes concentrações na microdureza dentinária. Seguindo a metodologia do trabalho anterior, os autores distribuíram os espécimes em 4 grupos: GI- EGTA 1\%; GII- EGTA 3\%; GIII- EGTA 5\%; GIV- agua destilada e deionizada. Apos análise da dureza Vickers, concluíram que as 3 soluções diminuíram significantemente a microdureza dentinária, sendo que a redução foi maior quanto maior a concentração do agente quelante.

Çalt; Serper (2002) estudaram a ação do EDTA na remoção da smear layer e seu efeito sobre a estrutura dentinária. Foram utilizados dentes unirradiculares 
instrumentados ate lima \#60. Os terços médios foram cortados longitudinalmente e cada metade da mesma raiz foi irrigada com $10 \mathrm{~mL}$ da solução de EDTA $17 \%$, durante 1 e 10 minutos, respectivamente. Observaram que com apenas 1 minuto de ação, a solução de EDTA foi eficiente na remoção da smear layer, e que a aplicação por 10 minutos causou erosão excessiva da dentina peritubular e intertubular.

Vogel (2002) relata em seu livro que o EDTA é um poderoso agente complexante e facilmente obtido comercialmente. Ressalta que a molécula de EDTA une-se ao íon metálico na razão de 1:1, ou ainda, 1 mol de EDTA quela o equivalente a 1 mol de íons metálicos.

Hülsmann et al. (2003) realizaram uma revisão da literatura sobre o emprego e função dos agentes quelantes na Endodontia. Os autores listaram diversas funções dessas substâncias como a desmineralização do tecido dentinário reduzindo a microdureza e facilitando a ação dos instrumentos, capacidade de aumentar a permeabilidade viabilizando a ação de medicamentos e, remoção da smear layer do canal radicular.

Fuentes et al. (2003) estudaram, por meio da dureza Vickers e Knoop, a microdureza da dentina coronária, classificada em superficial (dentina a $0,5 \mathrm{~mm}$ do esmalte) e profunda (dentina a $0,5 \mathrm{~mm}$ do corno pulpar mais alto). As medidas foram realizadas em cortes transversais de dentina das coroas de terceiros molares. Para a dureza Vickers, utilizaram cargas de 300 e $500 \mathrm{~g}$ durante 15 segundos e de 50 e $100 \mathrm{~g}$ para a Knoop. Ao final, verificaram que a dentina superficial apresenta, significantemente, maior microdureza que a região mais profunda, quando avaliada por meio de dureza Knoop. Quando mensuradas pela dureza Vickers, não houve diferença entre as regiões.

Haznedaroglu (2003) avaliou, por meio de MEV, a capacidade do ácido cítrico em remover a smear layer, em diferentes concentrações e pH. Observaram que o ácido cítrico em baixa concentração e pH original foi tão eficiente na limpeza das paredes do canal radicular, quanto o ácido aplicado em concentrações maiores.

Scelza et al. (2003) analisaram a complexação de íons $\mathrm{Ca}^{2+}$ do EDTA, EDTA-T e do ácido cítrico em função do tempo de aplicação. Dentes caninos foram instrumentados, tendo como solução irrigante o hipoclorito de sódio 5\%, e irrigação final os quelantes EDTA 17\%, EDTA-T 17\% e ácido cítrico 10\%, por 3, 10 e 15 minutos. Amostras das soluções foram submetidas à análise pela espectrofotometria de absorção atômica. Os resultados mostraram que a menor concentração de íons cálcio 
removidos foi observada com a solução de EDTA-T 17\%. A capacidade quelante do EDTA e do ácido cítrico foram semelhantes.

Uragami et al. (2003) descreveram a desidratação de álcoois por meio de complexo de membranas compostas de quitosana. Segundo os autores, a quitosana é um amino polissacarídeo, elaborada por desacetilação da quitina, encontrada a partir de cascas de caranguejo e camarão, que pode ser usado como material de separação de anticoagulantes, adsorventes e membranas.

Slutzky-Goldberg et al. (2004) estudaram o efeito do hipoclorito de sódio na microdureza da dentina radicular. Para isso, 42 discos de dentina de raízes de incisivos bovinos foram distribuídos em 6 grupos, variando-se a concentração da solução irrigante $(2,5$ e $6 \%)$ e o período de irrigação (5, 10 e 20 minutos). No grupo controle utilizou-se solução salina. As mensurações, no aparelho de microdureza Vickers, foram realizadas a $500 \mu \mathrm{m}, 1000 \mu \mathrm{m}$ e $1500 \mu \mathrm{m}$ da luz do canal radicular. Os resultados apontaram diminuição da microdureza em todas as distâncias analisadas para ambas as concentrações, no entanto, o hipoclorito de sódio 6\% a $500 \mu \mathrm{m}$ promoveu uma redução significantemente maior que o hipoclorito de sódio $2,5 \%$.

Machado-Silveiro et al. (2004) verificaram a capacidade do ácido cítrico $1 \%$ e $10 \%$, citrato de sódio $10 \%$ e EDTA $17 \%$ de remover íons cálcio da dentina radicular. As raízes de oito caninos superiores foram alargadas e seccionadas no terço cervical a 3 mm da embocadura do canal radicular, e posteriormente cada secção foi dividida em 4 partes e distribuídas conforme a solução a ser testada. Os espécimes foram imersos em recipientes contendo $5 \mathrm{~mL}$ da solução durante o período de 5, 10 e 15 minutos. Dois mililitros de cada solução foram coletados a cada período proposto e levados ao espectrômetro para análise da quantidade de íons cálcio removidos. Como resultado, os ácidos cítricos $1 \%$ e $10 \%$ removeram maior quantidade de íons cálcio que o EDTA e o citrato de sódio nos três períodos de análise. Estas duas últimas soluções apresentaram um declínio na remoção de cálcio com o tempo.

Ari et al. (2004) estudaram o efeito de diferentes soluções irrigantes na microdureza e rugosidade da dentina radicular. Noventa dentes anteriores inferiores foram cortados longitudinalmente. As 180 hemi secções obtidas foram distribuídas conforme os grupos: GI- $\mathrm{NaOCl} 5,25 \%$; GII- $\mathrm{NaOCl} 2,5 \%$; GIII- $\mathrm{H}_{2} \mathrm{O}_{2}$ 3\%; GIVEDTA 17\%; GV- clorexidina 0,2\%; GVI- agua destilada (controle). As soluções permaneceram sobre os espécimes por um período de 15 segundos. Todas as soluções 
com exceção da clorexidina reduziram a microdureza. $\mathrm{H}_{2} \mathrm{O}_{2}$ e clorexidina não apresentaram nenhum efeito na rugosidade da dentina.

Eldeniz et al. (2005) pesquisaram o efeito do EDTA e ácido cítrico na microdureza e rugosidade dentinária. Quarenta e cinco dentes foram cortados longitudinalmente. Cada hemi secção foi montada em um bloco de resina acrílica e receberam os seguintes tratamentos: GI- EDTA $17 \%$ por 150 segundos e em seguida $\mathrm{NaOCl} 5,25 \%$ por 150 segundos; GII- ácido cítrico $19 \%$ por 150 segundos e então, $\mathrm{NaOCl} 5,25 \%$ por 150 segundos; GIII- água destilada (controle). O grupo do ácido cítrico apresentou a maior redução da microdureza e os maiores valores de rugosidade.

Sousa; Silva (2005) verificaram o efeito desmineralizante do EDTA 1\% (pH 7,4), EGTA $1 \%(\mathrm{pH} \mathrm{7,4),} \mathrm{EGTA} \mathrm{1 \%} \mathrm{(pH} \mathrm{7,4),} \mathrm{CDTA} \mathrm{1 \%} \mathrm{(pH} \mathrm{7,4),} \mathrm{ácido} \mathrm{cítrico} \mathrm{1 \%}$ ( $\mathrm{pH} 1,0)$, ácido cítrico 1\% ( $\mathrm{pH} \mathrm{7,4)} \mathrm{e} \mathrm{soro} \mathrm{fisiológico} \mathrm{(controle).} \mathrm{Quarenta} \mathrm{e} \mathrm{oito} \mathrm{dentes}$ unirradiculares humanos foram instrumentados e distribuídos em grupos conforme a solução testada. A concentração de íons cálcio foi determinada por meio da espectrometria de absorção de massa. Os autores puderam verificar que o ácido cítrico em pH 1,0 foi a solução mais eficiente na remoção de íons cálcio quando comparada as demais. Nenhuma diferença foi observada entre o EDTA e EGTA, os quais removeram maior quantidade de cálcio que o CDTA e ácido cítrico em pH 7,4, este com efeito semelhante ao grupo controle.

Pérez-Heredia et al. (2006) avaliaram, por meio de MEV, a capacidade de limpeza de 3 soluções irrigantes ácidas apos a instrumentação rotatória e manual. Oitenta dentes humanos foram distribuídos aleatoriamente em 8 grupos. Quatro grupos foram preparados com instrumentação manual e os outros quatro com rotatória. As soluções irrigantes utilizadas foram: ácido cítrico plus $15 \%$ e $\mathrm{NaOCl} 2,5 \%$; EDTA plus $15 \%$ e $\mathrm{NaOCl} 2,5 \%$; ácido ortofosfórico plus e $\mathrm{NaOCl} 2,5 \%$; e $\mathrm{NaOCl} 2,5 \%$ (controle). As soluções ácidas associadas com o $\mathrm{NaOCl} 2,5 \%$ foram eficientes na eliminação da smear layer e debris não havendo diferença significante na remoção de smear layer entre as técnicas. $\mathrm{O} \mathrm{NaOCl} 2,5 \%$ não foi capaz de promover a limpeza.

Qing et al. (2006) analisaram a capacidade de limpeza e o efeito na microdureza da dentina radicular após o uso de algumas soluções irrigantes associadas ou não ao uso do ultra som. Quarenta e três dentes unirradiculares foram instrumentados e distribuídos em 5 grupos conforme a solução irrigante preconizada: GI- $\mathrm{NaOCl} 5,25 \%$ e $\mathrm{H}_{2} \mathrm{O}_{2} 3 \%$; GII- um ácido forte, patenteado como água ácida (AAE) com ultra som por 1 minuto, seguido de $\mathrm{NaOCl} 5,25 \%$; GIII- água destilada com uso de ultra som por 1 minuto; 
GIV-AAE com ultra som por 3 minutos seguido de NaOCl 5,25\%; GV- EDTA 15\% seguido de $\mathrm{NaOCl} 5,25 \%$. Os espécimes foram cortados longitudinalmente, sendo uma hemi secção preparada para análise em MEV e a outra para mensuração da microdureza Vickers. Os resultados mostraram que apenas os grupos IV e $\mathrm{V}$ foram capazes de diminuir a microdureza. Quanto à remoção da smear layer o grupo do EDTA mostrouse semelhante aos grupos II e IV.

Marques et al. (2006) avaliaram a capacidade de remoção da smear layer e de íons cálcio da dentina radicular apos irrigação com três soluções quelantes. Dezesseis dentes caninos foram instrumentados e a cada troca de lima utilizou-se $1 \mathrm{~mL}$ de solução quelante conforme os grupos: G1- EDTAC 17\%; GII- CDTA 17\%; GIII- EGTA 17\%. Ao final do preparo biomecânico foram coletados $8 \mathrm{~mL}$ de cada solução, os quais foram levados ao espectrofotômetro de absorção atômica para análise da quantidade de íons cálcio presentes. As raízes foram seccionadas longitudinalmente e preparadas para avaliação em MEV. Os resultados mostraram que o EDTAC e CDTA removeram a smear layer e íons cálcio da dentina de forma mais eficiente que a solução de EGTA. Em relação à limpeza entre os terços, não houve diferença entre eles.

De-Deus et al. (2006) estudaram o efeito do EDTA 17\%, EDTAC 17\% e ácido cítrico $10 \%$ na microdureza dentinária. Dezoito caninos superiores tiveram suas raízes cortadas transversalmente no terço médio, obtendo-se assim, discos de dentina com espessura de $4 \mathrm{~mm}$. Os espécimes foram distribuídos em 3 grupos de acordo com a solução a ser avaliada. As amostras receberam $50 \mu \mathrm{L}$ da solução que permaneceu sobre a dentina durante 1, 3 e 5 minutos. A mensuração da microdureza Vickers foi realizada antes do tratamento e imediatamente após cada período de aplicação. Os autores observaram que o ácido cítrico, em todos os momentos, foi menos efetivo que as demais soluções.

Akncbay et al. (2007) avaliaram a eficiência clínica da quitosana no tratamento de periodontite crônica. O gel de quitosana $1 \%$ com ou sem metronidazol $15 \%$ foi aplicado como auxiliar a raspagem e alisamento radicular, em comparação ao grupo controle que teve apenas a raspagem e alisamento realizados. Os autores relataram melhoras significativas nos parâmetros clínicos em todos os grupos, não havendo complicações relacionadas com a quitosana, sugerindo-se sua eficiência, bem como a sua biocompatibilidade, bioadesão e ação antimicrobiana.

De-Deus et al. (2007) realizaram um estudo longitudinal e quantitativo do poder de desmineralização da dentina promovido pelo Bio Pure MTAD, EDTA 17\% e ácido 
cítrico 5\%. Foram obtidos discos de dentina de aproximadamente $3 \mathrm{~mm}$ de espessura da região media da coroa de 9 molares superiores, e distribuídos em grupos conforme a solução testada. Por meio de um microscópio co-site obtiveram imagens, sempre da mesma região de dentina tratada pela solução teste nos períodos de 0, 15, 30, 60, 180 e 300 segundos. Os resultados mostraram que a desmineralização promovida pelo ácido cítrico e MTAD foi significantemente mais rápida que a do EDTA.

Oliveira et al. (2007) avaliaram o efeito da clorexidina e do hipoclorito de sódio na microdureza da dentina radicular. As raízes de 30 pré-molares foram instrumentadas até a lima \#50 e irrigadas com soro fisiológico. Em seguida seccionaram as raízes transversalmente nos terços cervical, médio e apical e montaram em blocos de resina acrílica. Utilizou-se $1 \mathrm{~mL}$ de cada solução na luz do canal radicular por 15 minutos e aferiu-se a microdureza nas distâncias de $500 \mu \mathrm{m}$ e $1000 \mu \mathrm{m}$ da luz do canal radicular. Os resultados evidenciaram que a clorexidina e o $\mathrm{NaOCl}$ diminuíram a microdureza nas duas distancias estudadas. Não houve diferença na redução da microdureza entre os três terços avaliados, independentemente da distância.

Papagianni (2007) realizou uma revisão da literatura focada na fermentação do ácido cítrico pelo fungo A. niger. Segundo o autor, a produção de ácido cítrico requer uma combinação de concentrações excessivas de fonte de carbono, íons de hidrogênio e oxigênio, além de baixas concentrações de traços de metais e fosfato. $\mathrm{O}$ autor salientou que o A. niger tem capacidade de produzir citrato por uma via glicolítica ativa.

Sayin et al. (2007) verificaram o efeito do EDTA, EGTA, EDTAC e $\mathrm{HCl} /$ tetraciclina na microdureza dentinária. Trinta raízes de dentes unirradiculares foram divididas longitudinalmente, incluídas em resina acrílica e impermeabilizadas, deixando apenas a luz do canal exposta. Os espécimes foram distribuídos em grupos conforme a solução testada: GI- $\mathrm{NaOCl}$ 2,5\%; GII- EDTA 16\%; GIII- EDTAC 15\%; GIV-EGTA 17\%; GV- HCl/tetraciclina 1\%, permanecendo imersos durante 5 minutos. Ao final, com exceção do GI, os espécimes receberam um tratamento com $\mathrm{NaOCl}$ (tratamento combinado), sendo lavados, em seguida, com $10 \mathrm{~mL}$ de água destilada. As amostras foram levadas ao microdurômetro, onde receberam 3 endentações com carga de 200 g por 20 segundos, para cada terço (cervical, médio e apical). Os autores observaram que todos os grupos reduziram a microdureza. O uso do EDTA isolado e combinado com hipoclorito de sódio foi significantemente mais eficiente na redução da microdureza que o dos demais grupos, e os tratamentos combinados com $\mathrm{NaOCl}$ 
reduziram a microdureza, numa proporção muito maior em relação ao uso da solução empregada isoladamente.

Pérez-Heredia et al. (2008) avaliaram o poder de descalcificação da dentina promovida pelas soluções de EDTA $15 \%$, ácido cítrico $15 \%$ e ácido fosfórico 5\%. Dez raízes de incisivos centrais superiores foram instrumentadas e sofreram dois cortes transversais de $2 \mathrm{~mm}$ de espessura no terço cervical. Cada corte de dentina foi seccionado ao meio, totalizando 40 hemi secções, as quais foram distribuídas em 4 grupos, conforme a solução testada. Utilizou-se $\mathrm{NaOCl} 2,5 \%$ como controle. Os espécimes foram imersos em $20 \mathrm{~mL}$ da solução a ser testada por um período de 5, 10 e 15 minutos. Decorridos os períodos propostos, as soluções foram analisadas por meio de um espectrômetro de absorção atômica, para verificar a quantidade de íons cálcio presente. Os autores observaram que as 3 soluções promoveram a descalcificação da dentina principalmente nos primeiros 5 minutos de ação, no entanto, o EDTA e ácido cítrico foram significantemente melhores que o ácido fosfórico nos 3 períodos.

De-Deus et al. (2008a) verificaram o efeito desmineralizante do EDTA 17\%, EDTAC $17 \%$ e ácido cítrico $1 \%$. Aplicou-se $1 \mathrm{~mL}$ da solução a ser testada sobre discos de tecido dentinário obtidos da porção cervical da raiz de molares superiores, nos tempos de 15, 30, 60, 180 e 300 segundos. Na sequência, os espécimes foram lavados com $2 \mathrm{~mL}$ de água destilada. Os resultados mostraram que o ácido cítrico promoveu a maior desmineralização em todos os períodos avaliados, exceto aos 300 segundos onde o EDTA mostrou-se similar.

De-Deus et al. (2008b) pesquisaram a capacidade de desmineralização da dentina pelo EDTA associado ou não a diferentes agentes auxiliares. Foram confeccionados, a partir do terço cervical de doze molares superiores, discos de dentina com $3 \mathrm{~mm}$ de espessura. As amostras foram submetidas à formação de smear layer e posteriormente distribuídas em 4 grupos: GI- EDTA 17\%; GII- EDTAC 17\%; GIIIEDTA-T 17\%; GIV-Smear Clear ${ }^{\circledR}$. Por meio da microscopia óptica co-site verificou-se o efeito desmineralizante das soluções nos períodos de 15, 30, 60, 180 e 300 segundos. Observou-se que o EDTA aplicado isoladamente promoveu efeito quelante significantemente maior dentre as soluções para todos os tempos propostos.

De-Deus et al. (2008c) estudaram a capacidade quelante do ácido etidrônico (HEBP) comparada a do EDTA. Discos de dentina coronal de terceiros molares foram polidos e submetidos a um tratamento para formação de smear layer sobre a superfície. Posteriormente, os espécimes foram submetidos à ação das seguintes soluções 
quelantes: HEBP 9\%, HEBP 18\% e EDTA 17\%. Durante o tratamento dos espécimes obtiveram-se 16 imagens de cada área de dentina desmineralizada no período de 60 , 180, 300 e 600 segundos. Os autores observaram que o HEBP, nas duas concentrações, removeu a smear layer após 300 segundos de ação, ao passo que o EDTA promoveu o mesmo efeito em apenas 60 segundos. Durante todo o experimento o EDTA mostrou-se mais eficiente que o HEBP $18 \%$ e este, mais eficiente que o HEBP 9\%. Concluíram que a descalcificação promovida pelo HEBP foi significantemente menor à do EDTA.

Reis et al. (2008) pesquisaram o efeito de altas concentrações de ácido cítrico na dentina humana. A porção cervical das raízes de molares superiores foi exposta e submetida ao tratamento com ácido cítrico 1, 5 e 10\% e EDTA 17\%. O período de observação dos espécimes variou de 15 a 300 segundos. Posteriormente, os espécimes foram analisados, por meio de MEV e, microscopia óptica co-site. Os autores verificaram que as soluções de ácido cítrico apresentaram o maior efeito quelante, sendo que quanto maior a concentração, maior a desmineralização.

Lottanti et al. (2009) avaliaram a desmineralização da dentina e a remoção da smear layer após a irrigação dos espécimes com as seguintes soluções quelantes: GI$\mathrm{NaOCl} 1 \%$ durante a biomecânica e água deionizada, após; GII- NaOCL 1\% durante o preparo e EDTA na irrigação final; GIII- mistura de $\mathrm{NaOCl} 2 \%$ e ácido etidrônico (1:1) durante e após a instrumentação; GIV- $\mathrm{NaOCl} 1 \%$ durante a biomecânica e ao final, ácido peracético $2,25 \%$. O volume da solução utilizada durante a instrumentação foi de $10 \mathrm{~mL}$ por 15 segundos, seguido de $5 \mathrm{~mL}$ da solução empregada na irrigação final por 3 minutos mais $5 \mathrm{~mL}$ de água deionizada. Os autores observaram que a mistura de $\mathrm{NaOCl}$ e ácido etidrônico removeu uma menor quantidade de íons cálcio que os grupos anteriores e mostrou-se semelhante ao grupo do $\mathrm{NaOCl}$, o qual não teve nenhum efeito desmineralizante. Os grupos do EDTA e ácido peracético mostraram-se semelhantes entre si. Todos os protocolos de irrigação resultaram em remoção significante da smear layer. No terço cervical o EDTA apresentou resultado ligeiramente superior ao ácido peracético, porém, nos terços médio e apical as 3 soluções avaliadas comportaram-se de forma semelhante entre si.

Spanó et al. (2009) avaliaram a capacidade de remoção da smear layer promovida pela ação de agentes quelantes e desmineralizantes e quantificaram a concentração de íons cálcio presentes nessas soluções após a utilização no canal radicular. Realizada a biomecânica os dentes foram distribuídos em 7 grupos conforme a irrigação final: GI- EDTA 15\%; GII- ácido cítrico 10\%; GIII- citrato de sódio 10\%; 
GIV- vinagre de maçã; GV- ácido acético 5\%; GVI- ácido málico 5\%; GVII- sem irrigação. Utilizaram-se $5 \mathrm{~mL}$ da solução teste por 5 minutos. Durante a irrigação final, a solução percorria todo o canal radicular, sendo coletada, após passar pelo forame, em um frasco plástico. As amostras foram enviadas para análise por meio de espectrofotometria. Os espécimes foram clivados longitudinalmente, em duas hemissecções e enviados para avaliação em MEV. Os autores verificaram que o EDTA e o ácido cítrico removeram a smear layer de forma semelhante. As demais soluções não foram eficientes para esta finalidade. O grupo do EDTA teve a maior quantidade de íons cálcio removidos seguido ácido cítrico, enquanto que o citrato de sódio foi o grupo que apresentou as menores quantidades.

Patil; Uppin (2011) avaliaram a microdureza e rugosidade da superfície da dentina radicular após tratamento com as seguintes soluções irrigantes: hipoclorito de sódio 2,5\% e 5\%, peróxido de hidrogênio 3\%, EDTA 17\%, clorexidina 0,2\% e água destilada (controle). Os autores utilizaram incisivos superiores e inferiores seccionados longitudinalmente e incluídos em blocos de resina acrílica. Cada solução permaneceu sobre o espécime por 15 minutos. Os resultados mostraram que todas as soluções irrigantes, com exceção da clorexidina $0,2 \%$, diminuíram a microdureza dentinária. $\mathrm{O}$ peróxido de hidrogênio $3 \%$ e a clorexidina $0,2 \%$ não alteraram a rugosidade da superfície dentinária.

Prado et al. (2011) estudaram a capacidade do ácido fosfórico 37\%, ácido cítrico $10 \%$ e do EDTA $17 \%$ em remover a smear layer dentinária. Cinquenta e dois caninos humanos foram instrumentados e irrigados com hipoclorito de sódio a cada troca de instrumento, e posteriormente separados em grupos conforme a solução testada. Após análise por MEV, observou-se que as soluções foram eficientes em todos os terços (cervical, médio e apical), quando aplicada por 3 minutos. Quanto à integridade dentinária, todas as substâncias geraram algum grau de erosão nos terços cervical e médio durante a irrigação por 1 minuto ou mais.

Cruz-Filho et al. (2011) verificaram o efeito de diferentes soluções quelantes na microdureza da camada mais superficial da dentina que reveste o canal radicular. Trinta e cinco dentes unirradiculares foram instrumentados com sistema rotatório e irrigação com hipoclorito de sódio. Após o preparo biomecânico os espécimes foram seccionados longitudinalmente e incluídos em blocos de resina. Os grupos foram distribuídos conforme a irrigação final dos espécimes: EDTA 15\%, ácido cítrico 10\%, ácido málico $5 \%$, ácido acético 5\%, vinagre de maçã, citrato de sódio 5\% e no grupo controle não 
houve irrigação. Utilizaram $50 \mu \mathrm{L}$ de cada solução por 5 minutos. Posteriormente os espécimes foram levados para aferição no aparelho de microdureza Knoop. Os autores concluíram que, com exceção do citrato de sódio 5\%, todas as soluções testadas diminuíram a microdureza dentinária. O EDTA $15 \%$ e o ácido cítrico $10 \%$ foram os mais eficientes. 
Proposição 28

\section{PROPOSIÇÃO}

O objetivo do presente estudo propõe-se avaliar o efeito das soluções de Quitosana $0,2 \%$, EDTA $15 \%$ e Ácido Cítrico $10 \%$ sobre a microdureza da dentina radicular humana. 


\section{MATERIAL E MÉTODO}

Após a submissão e aprovação do presente projeto pelo Comitê de ética em Pesquisa (CEP) da Faculdade de Odontologia de Ribeirão Preto da Universidade de São Paulo (FORP-USP), foram utilizados 10 dentes incisivos centrais superiores cedidos pelo Banco de Dentes da mesma instituição.

Os dentes foram mantidos em solução de timol $0,1 \%$ em geladeira a $9^{\circ} \mathrm{C}$ até o momento do experimento, quando, então, foram lavados em água corrente por 24 horas para remoção do remanescente da solução de timol presente sobre a superfície dos espécimes.

\section{1- Confecção do corpo de prova}

Inicialmente os dentes foram radiografados no sentido próximo proximal, com objetivo de constatar a presença de um único canal radicular. Na sequência, tiveram a coroa seccionada na junção esmalte-cemento (Figura 1a), por meio de disco de 
carburundum acoplado à peça reta do micro motor (Dabi Atlante, Ribeirão Preto, São Paulo, Brasil).

A porção da raiz remanescente foi colocada em um molde de silicone, no qual se inseriu resina acrílica autopolimerizavel, envolvendo toda estrutura da raiz (Figura 1b). Após a polimerização, o bloco formado raiz/resina (Figura 1c) foi acoplado a uma máquina de corte (Struers A/S, Copenhagen, Dinamarca), para secção transversal da porção cervical (Figura 2).

Foram obtidos 3 cortes da dentina com espessura de $1 \mathrm{~mm}$ cada, ainda inclusos em resina. Nesta fase, removia-se a camada de acrílico que permanecia em volta dos cortes e os colocava em uma placa de Petri, a qual continha uma gaze umedecida em água. Os cortes externos foram desprezados, utilizando-se o corte intermediário para o estudo, ou seja, o segundo corte (Figura 1d). Esse corte foi dividido em quatro partes (Figura 1e), por meio de uma lâmina de bisturi n ${ }^{\circ} 15$.

Cada quadrante obtido teve sua superfície cervical umectada com vaselina líquida e colocado no centro de um anel de metal disposto sobre uma lâmina de cera utilidade. O interior do anel metálico contendo o quadrante de dentina foi preenchido com resina acrílica autopolimerizável, confeccionando-se assim, o corpo de prova.

No total foram obtidos 4 corpos de prova de cada raiz, um para cada tratamento a ser realizado (figura 1f).

A superfície do corpo de prova foi lixada com lixas d’água de granulação 400, 500 e 600 sob água corrente e na sequência, polida em uma politriz (Arotec, São Paulo, SP, Brasil), dotada de um disco de feltro umedecido (Figura 3), associado a uma pasta de alumínio (Arotec, São Paulo, SP, Brasil).

Durante a fase de polimento, a superfície do corpo de prova era examinada, de tempo em tempo, por meio de uma lupa com aumento de $30 \mathrm{X}$, no sentido de verificar a lisura do conjunto. O polimento era considerado adequado quando a superfície apresentava-se sem riscos e irregularidades. Concluída esta fase, os espécimes foram colocados em uma placa de Petri contendo uma gaze umedecida, até o momento do tratamento com as soluções propostas. 


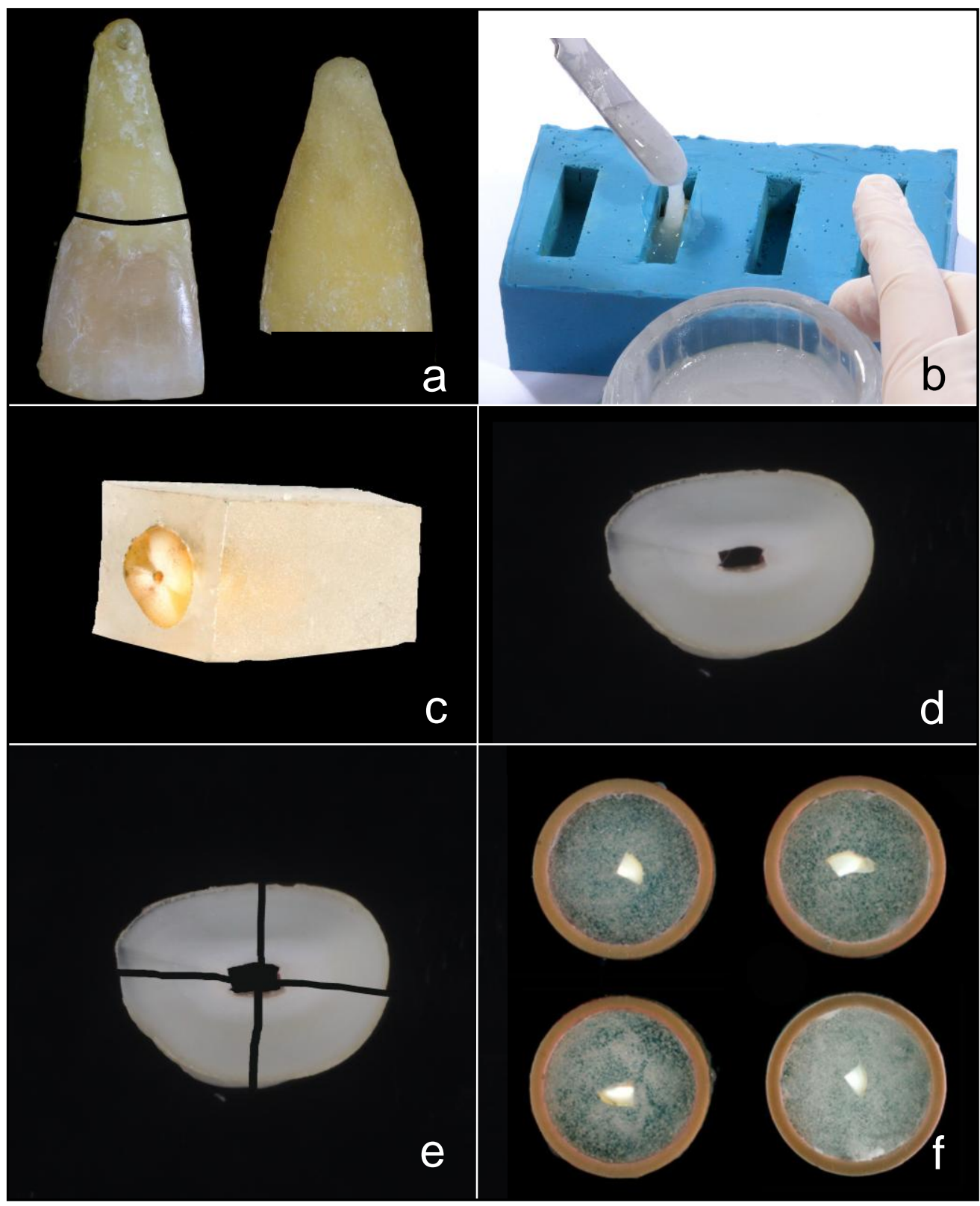

Figura 1 - Sequência da confecção do corpo de prova; a) secção da coroa dental; b) inclusão da raiz em acrílico autopolimerizável; c) conjunto raiz/resina; d) vista oclusal do disco de dentina; e) disco de dentina seccionado em quadrantes; f) vista oclusal dos corpos de prova. 


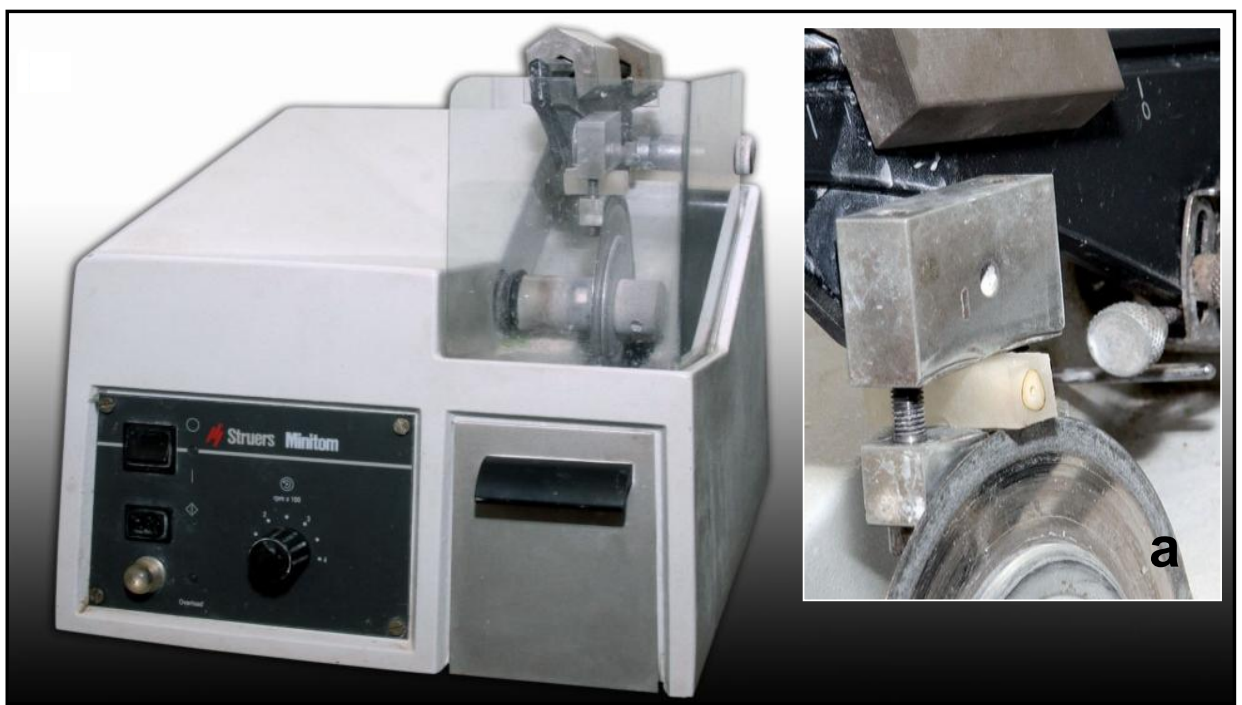

Figura 2 - Máquina de corte de tecido duro Strues; a) detalhe do bloco formado pela raiz/resina acoplado a máquina.

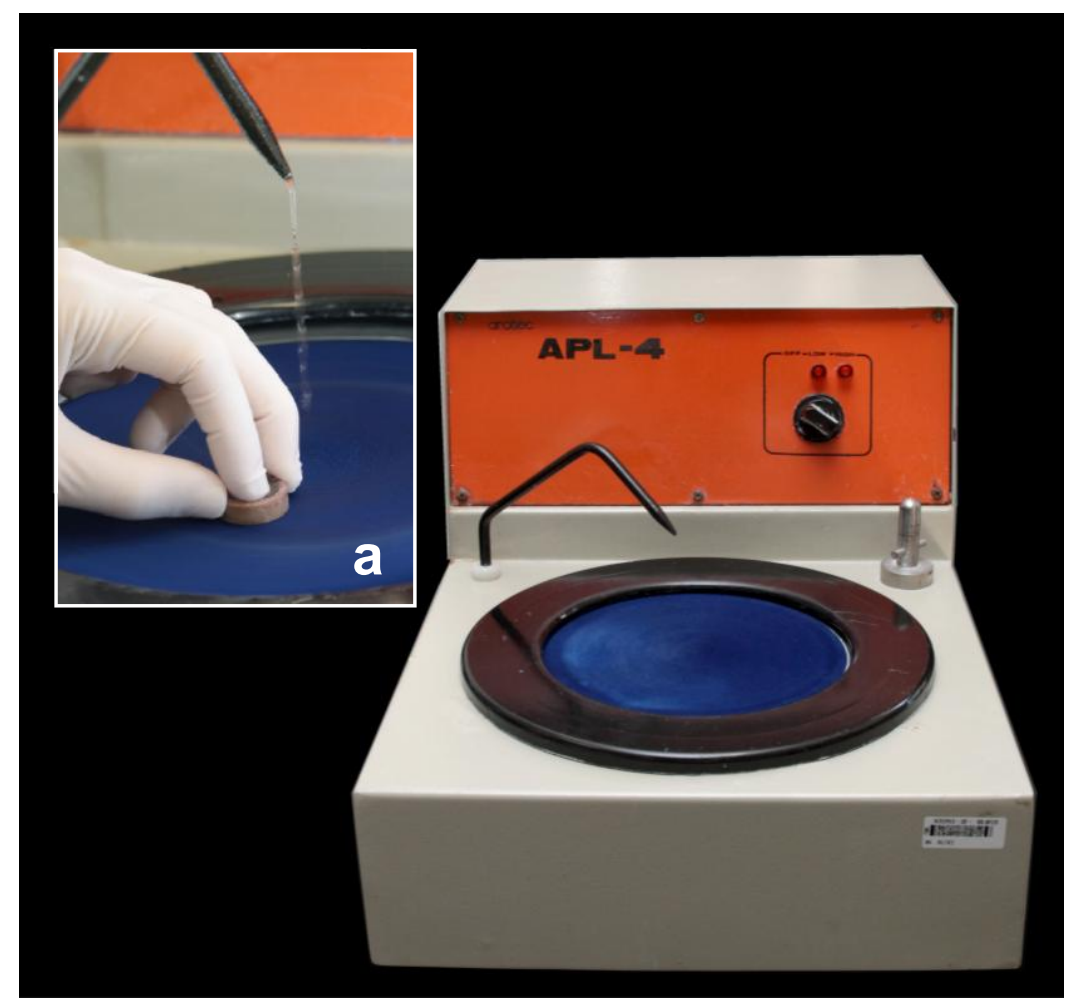

Figura 3 - Politriz Arotec; a) detalhe do polimento do corpo de prova. 


\section{2- Tratamento dos corpos de prova}

Cada corpo de prova resultante dos 4 quadrantes do disco de dentina foi destinado a um grupo. Assim, formaram-se 4 grupos, um para cada solução a ser testada, com 10 corpos de prova para cada grupo $(n=10)$ : G1- EDTA 15\%; G2- Ácido Cítrico 10\%; G3- Quitosana 0,2\% e G4- controle

As soluções utilizadas no experimento foram aviadas no Laboratório de Pesquisa de Endodontia do Departamento de Odontologia Restauradora da FORP-USP.

Cada corpo de prova, respectivo de seu grupo, recebeu, por meio de uma micropipeta automática, $50 \mu \mathrm{L}$ da solução por um período de 5 minutos. $\mathrm{O}$ tempo de aplicação foi quantificado por um cronômetro digital (Casio, Tóquio, Japão).

Decorrido o tempo estipulado o corpo de prova era lavado, imediatamente, com água destilada e em seguida, seco com gaze.

O grupo controle não recebeu tratamento com nenhum tipo de solução.

\section{3- Leitura da microdureza}

Para mensuração da microdureza da dentina utilizou-se um microdurômetro de dureza Knoop (Shimadzu HMV-2000, Shimadzu Corporation, Kyoto, Japão)(Figura 4), com carga de 10 gramas durante 15 segundos.

Inicialmente, regulou-se a trajetória de mensuração da microdureza, por meio de um recurso do próprio microdurômetro, de tal forma, que ao se posicionar o corpo de prova, a demarcação da microdureza iniciava-se na porção de dentina próxima ao canal radicular seguindo uma linha reta em direção à dentina adjacente ao cemento. No intervalo compreendido entre este trajeto foi possível obter 3 endentações com espaço entre elas de $200 \mu \mathrm{m}$. Após a demarcação do corpo de prova, a imagem de cada endentação era fornecida na tela do computador acoplado ao microdurômetro (Figura 5), possibilitando a mensuração. 
Os valores da microdureza foram anotados e somados, estabelecendo-se uma média para cada espécime. Montou-se, então, um arquivo de dados para cada grupo conforme a solução irrigante utilizada.

Os arquivos de dados contendo os valores médios da microdureza dentinária foi submetido à análise estatística, por meio do software BioEstat versão 5.0.

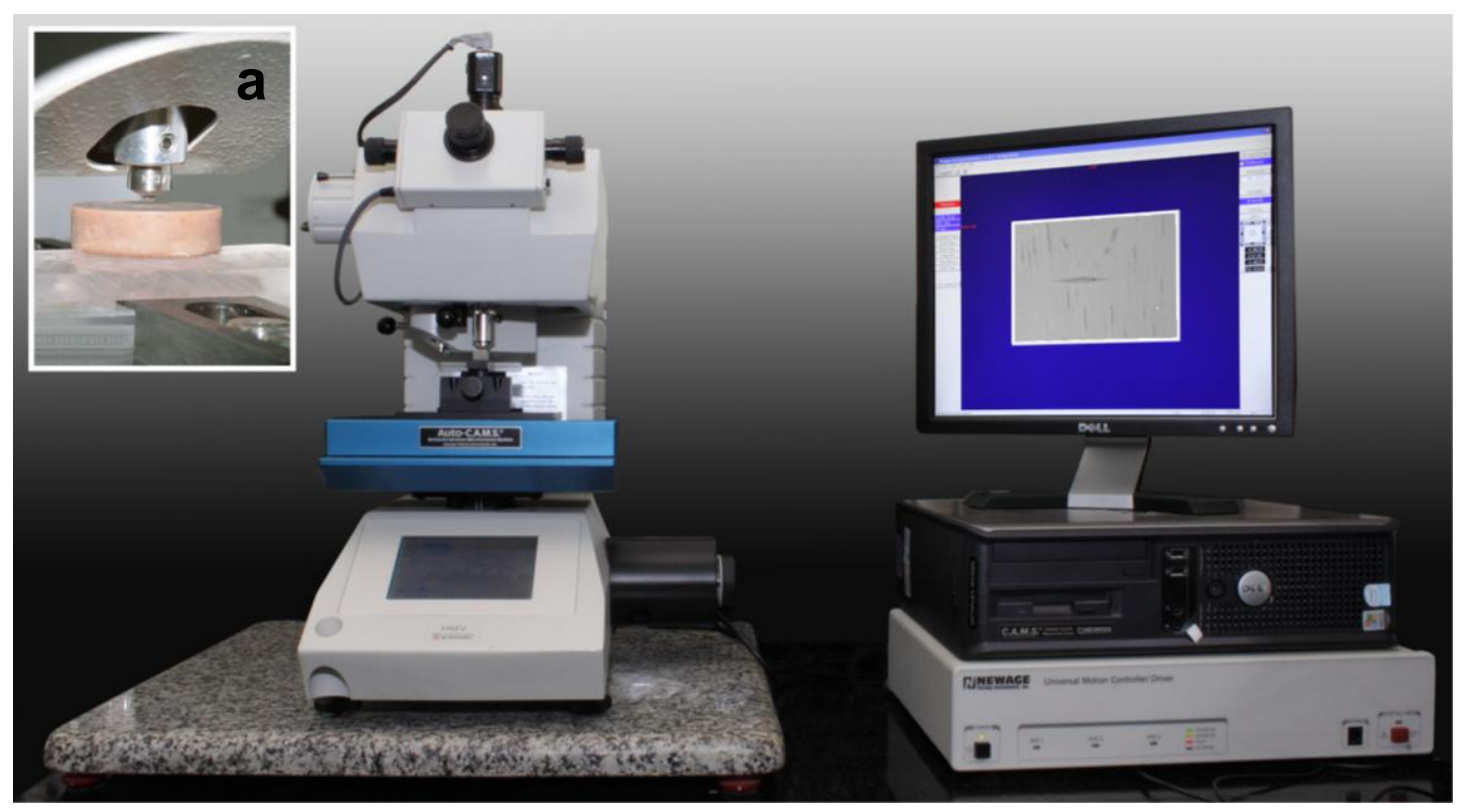

Figura 4 - Microdurômetro Shimadzu HMV-2000; a) detalhe do corpo de prova colocado no aparelho.

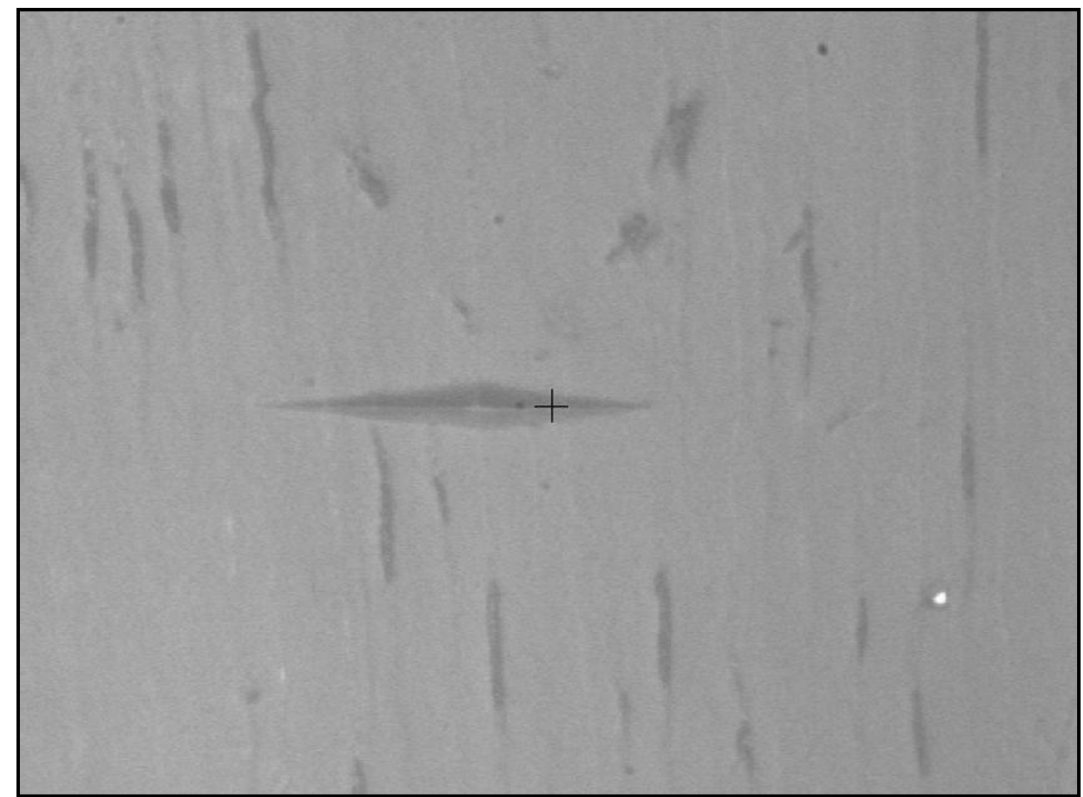

Figura 5 - Imagem da endentação visualizada na tela do microdurômetro. 


\section{RESULTADOS}

Os 40 dados amostrais utilizados neste experimento representam os valores médios da microdureza da dentina (Knoop) mensurada após aplicação das soluções quelantes. Esse número total de dados resulta do produto fatorial de quatro soluções (EDTA, ácido cítrico, quitosana, controle), 10 dentes e uma média por dente: 4 x 10 x 1 $=40$.

Foram obtidas 3 medidas de microdureza para cada corpo de prova, das quais calculou-se uma média. Os valores médios obtidos estão expressos na Tabela 1. 
Tabela 1 - Valores médios da dureza Knoop conforme a solução utilizada.

\begin{tabular}{c|c|c|c|c}
\hline \multirow{2}{*}{ Dentes } & \multicolumn{4}{|c}{ Soluções } \\
\cline { 2 - 5 } & EDTA & Ac. Cítrico & Quitosana & Controle \\
\hline 01 & 22,9 & 19,4 & 27,8 & 33,7 \\
02 & 15,4 & 19,5 & 29,1 & 34,4 \\
03 & 19,5 & 25,1 & 30,5 & 41,6 \\
04 & 25,8 & 28,1 & 29,3 & 40,2 \\
05 & 34,1 & 16,3 & 33,7 & 42,7 \\
06 & 33,7 & 18,2 & 22,9 & 34,7 \\
07 & 25,5 & 17,6 & 22,0 & 43,6 \\
08 & 16,4 & 13,0 & 14,3 & 45,0 \\
09 & 19,0 & 15,5 & 20,5 & 17,8 \\
10 & 32,2 & 20,7 & 15,7 & 35,7 \\
& $24,4 \pm 7,0$ & $19,3 \pm 4,4$ & $24,5 \pm 6,5$ & $36,9 \pm 7,9$ \\
\hline
\end{tabular}

As médias da Tabela 1 foram submetidos à análise estatística, por meio do software BioEstat 5.0, com nível de significância de 5\% $(\alpha=0,05)$. O programa evidenciou que a amostra testada apresentou distribuição normal. Tal informação aliada ao modelo matemático do experimento faculta a realização do teste paramétrico de Análise de Variância (one-Way ANOVA) seguido pelo teste complementar de TukeyKramer. A Tabela 2 apresenta os resultados da Análise de Variância.

Tabela 2 - Resultados da Análise de Variância.

\begin{tabular}{c|c|c|c|c|c}
\hline $\begin{array}{c}\text { Fontes de } \\
\text { variação }\end{array}$ & $\begin{array}{c}\text { Soma dos } \\
\text { quadrados }\end{array}$ & $\begin{array}{c}\text { Grau de } \\
\text { liberdade }\end{array}$ & $\begin{array}{c}\text { Quadrado } \\
\text { médio }\end{array}$ & Valor de F & Valor de p \\
\hline Tratamentos & 16,8 e+02 & 3 & 560,097 & 12,8272 & $<0,0001$ \\
Resíduos & 15,7 e+02 & 36 & 43,665 & & \\
\hline Total & 32,5 & 39 & & & \\
\hline
\end{tabular}

A Análise de Variância evidenciou que a diferença entre as medianas é bastante significante, uma vez que o valor de p calculado é muito inferior a 0,05 ( $p<0,0001$ ). Com a finalidade de esclarecer quais dentre os tratamentos apresentavam diferenças entre si, realizou-se o teste complementar de Tukey-Kramer, o qual pode ser visto na Tabela 3. 
Tabela 3 - Teste de Tukey entre soluções.

\begin{tabular}{lcc}
\hline Soluções & Médias & Valor crítico $\alpha=0,05$ \\
\hline EDTA & $24,45 \mathbf{\Delta}$ & 3,813 \\
Ac. Cítrico & $19,34 \mathbf{\Delta}$ & \\
Quitosana & $24,58 \mathbf{\Delta}$ & \\
Controle & $36,94 \mathbf{\Delta}$ & \\
\hline
\end{tabular}

Símbolos diferentes representam valores estatisticamente diferentes.

A análise do teste complementar de Tukey-Kramer possibilitou a composição das soluções quelantes e desmineralizantes avaliadas em dois grupos distintos. Um grupo formado pelas soluções quelantes e desmineralizantes e outro constituído pelo controle. Todas as soluções avaliadas apresentaram capacidade de reduzir a microdureza dentinária, de forma estatisticamente semelhante entre elas, porém diferente estatisticamente do grupo controle $(\mathrm{p}<0,01)$.

A Figura 6 ilustra o gráfico da diferença entre as médias entre os grupos estudados e o grau de significância entre elas.

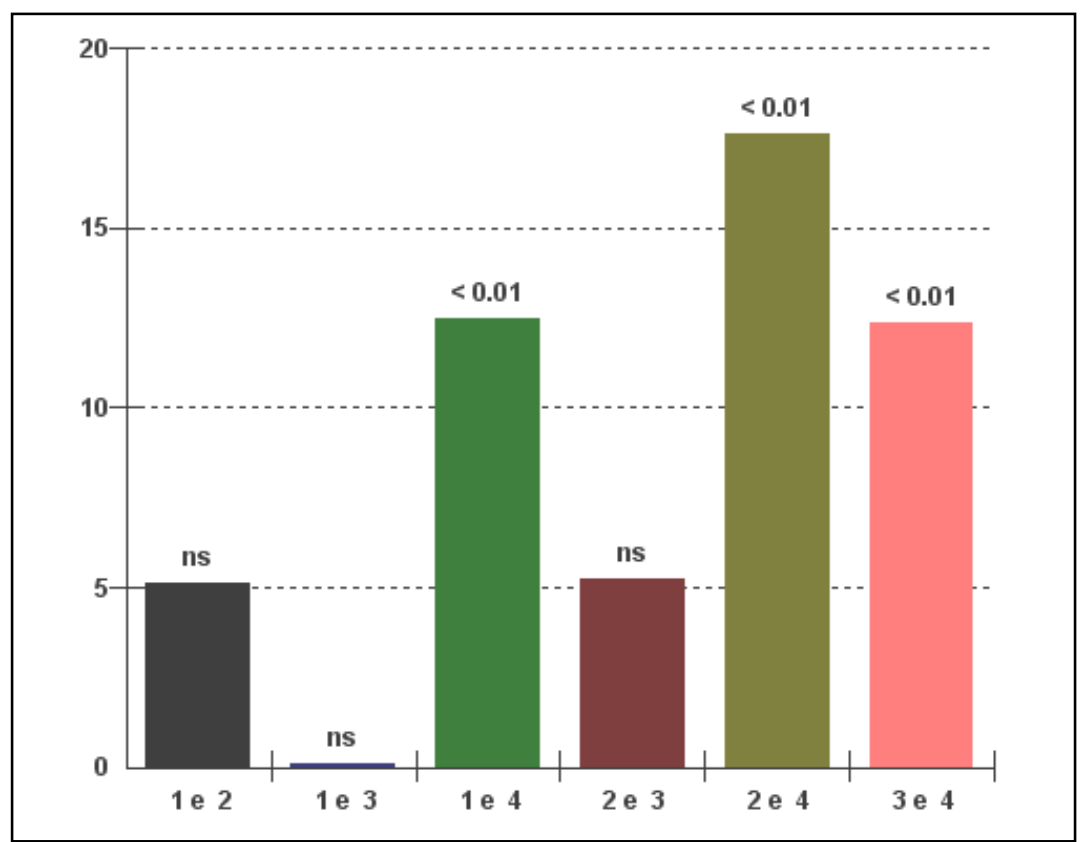

Figura 6- Representação gráfica da diferença entre as médias com o grau de significância (G1-EDTA; G2- ác. cítrico; G3- quitosana e G4-controle). 
Os estudos do efeito das soluções quelantes e ou desmineralizantes sobre a microdureza da dentina radicular empregam diferentes metodologias. Dentre as mais utilizadas destaca-se o emprego de discos de dentina obtidos através de cortes transversais da raiz de dentes bovinos (SLUTZKY-GOLDBERG et al., 2004) ou humanos (FAIRBANKS et al., 1997; CRUZ-FILHO et al., 1996; SALEH; ETTMAN, 1999; CRUZ-FILHO et al., 2001; CRUZ-FILHO et al., 2002; ARI et al., 2004; ELDENIZ et al., 2005; QING et al., 2006; De-DEUS et al., 2006; SAYIN et al., 2007; PÉREZ-HEREDIA et al., 2008; PATIL; UPPIN, 2011). Nesses experimentos a mensuração da microdureza é realizada na porção de dentina localizada entre o tecido cementário e a camada de pré-dentina que recobre o longo eixo do canal radicular. Recentemente, Cruz-Filho et al. (2011) propuseram uma nova metodologia na qual a medida da microdureza é realizada diretamente na porção de dentina que reveste o canal radicular. Os autores salientaram que a solução irrigante utilizada durante a fase do preparo biomecânico entra em contato, inicialmente, com a dentina das paredes do canal radicular. Dessa forma, os resultados obtidos pela metodologia sugerida estariam mais próximos da realidade clínica. 
No presente trabalho utilizou-se para a avaliação da microdureza dentinária discos de dentina de dentes humanos. Apesar da vantagem já mencionada na metodologia sugerida por Cruz-Filho et al. (2011), os resultados obtidos por esses autores foram semelhantes à outros trabalhos que empregaram metodologia semelhante a do presente estudo (SCELZA et al., 2003; SAYIN et al., 2007). O disco de dentina é simples, rápido, e fácil de obter, não apresentando maiores complexidades no seu preparo.

A microdureza dos materiais pode ser avaliada por meio da dureza Vickers ou Knoop. Fuentes et al. (2003) relataram que a região da dentina próxima ao esmalte quando mensurada por meio da dureza Knoop apresenta maior dureza que a porção de dentina próxima ao corno pulpar. No entanto, quando utilizada a dureza Vickers, a microdureza das mesmas regiões foram semelhantes, não apresentando diferença entre elas. Pashley et al. (1985) verificaram que microdureza da dentina radicular diminui quando a mensuração é realizada da dentina periférica, ou seja, próxima ao esmalte dental, para a região mais interna. O número de túbulos dentinários próximo à polpa é maior, oferecendo menor resistência nessa região (BURROW et al., 1994). Baseado nos achados dos trabalhos anteriores, para o presente estudo, pareceu mais coerente a avaliação da microdureza por meio da dureza Knoop.

A escolha do EDTA $15 \%$ como uma das soluções a ser avaliada deveu-se à comprovada capacidade desse agente quelante em reduzir a microdureza da dentina, tornando-se solução referencial nos estudos das soluções desmineralizantes (SALEH; ETTMAN, 1999; ARI et al., 2004; ELDENIZ et al., 2005; De-DEUS et al., 2006; SAYIN et al., 2007).

O ácido cítrico é um ácido orgânico fraco, bastante eficiente na remoção da smear layer e smear plug das paredes do canal radicular (SALAMA; ABDELMEGID, 1994; REIS et al., 2008; SPANÓ et al., 2009). Segundo alguns autores a capacidade desse ácido de desmineralizar o tecido dentinário é maior e mais rápida que a do EDTA (MACHADO-SILVEIRO et al., 2004; SOUSA; SILVA, 2005; De-DEUS et al., 2008a).

A quitosana, polissacarídeo natural obtido por desacetilação da quitina, possui alta capacidade quelante, além de ser dotada de propriedades de biocompatibilidade, biodegradabilidade, bioadesão e atoxidade às células humanas (KURITA, 1998; URAGAMI et al., 2003; SENEL et al., 2000; AKNCBAY et al., 2007). Essa substância em função das suas características pode ser uma alternativa viável dentre as soluções quelantes utilizadas na Odontologia. Verificar o efeito da quitosana sobre a microdureza 
da dentina radicular foi uma iniciativa para se obter embasamento e conhecimento da ação desmineralizante desse agente sobre o tecido dental.

A Tabela 3, mostra o teste de Tukey entre as soluções, pelo qual verifica-se que todas as soluções avaliadas foram capazes de reduzir a microdureza da dentina radicular de forma semelhante entre si e diferente estatisticamente do grupo controle.

A redução da microdureza da dentina promovida pelo EDTA é proveniente da propriedade de quelação dessa solução. O cálcio do tecido dentinário reage, por meio de força eletrostática, com a molécula de EDTA formando um complexo entre o agente quelante e o íon metálico (HÜLSMANN et al., 2003). O efeito redutor do EDTA sobre a microdureza foi relatado por Sayin et al. (2007). Os autores verificaram que a solução de EDTA acrescida de cetavlon (tensoativo), associada ou não ao hipoclorito de sódio é capaz de reduzir, significantemente, a microdureza dentinária em comparação a outros agentes quelantes específicos de íons cálcio. O efeito redutor do EDTAC sobre a dentina ocorre no primeiro minuto de aplicação da solução (CRUZ-FILHO et al., 1996). No entanto, no presente estudo, a ação desmineralizante do EDTA foi estatisticamente igual à do ácido cítrico e da quitosana.

O ácido cítrico reage rapidamente com o cálcio resultando o citrato de cálcio (PAPAGIANNI, 2007). Essa reação forma-se na razão de 1:1,5, ou seja, uma porção de ácido cítrico para uma e meia de íon cálcio. Em contrapartida, a molécula de EDTA une-se ao íon metálico na razão de 1:1, ou ainda, 1 mol de EDTA quela o equivalente a 1 mol de íons cálcio (VOGEL, 2002). Pela análise química entre a razão de ambas as soluções, teoricamente, o ácido cítrico deveria promover uma desmineralização da dentina maior que a do EDTA. Apesar de existir uma diferença entre as médias das medidas da microdureza entre o ácido cítrico $(19,34)$ e EDTA $(24,45)$, o teste estatístico mostrou não haver significância entre elas. Dessa forma, a igualdade em relação a capacidade de reduzir a microdureza entre as duas soluções pode ser explicada pela biodisponibilidade do cálcio. Esse elemento na dentina não se encontra disponível na forma de íon, mas sim como um complexo na forma de hidroxiapatita, impedindo, provavelmente, que a reação do ácido cítrico com o cálcio seja completa.

Os resultados obtidos neste estudo estão em concordância aos verificados no trabalho de Cruz-Filho et al. (2011). Os autores avaliaram o efeito do EDTA 15\%, ácido cítrico 10\%, ácido málico 5\%, ácido acético 5\%, citrato de sódio $10 \%$ e vinagre de maçã sobre a microdureza da dentina que reveste o longo eixo do canal radicular. Verificaram 
que o EDTA e ácido cítrico foram as soluções mais eficientes sem, no entanto, apresentar diferença entre si.

Spanó et al. (2009) estudaram a capacidade de limpeza e quantidade de íons cálcio removidos do canal radicular, por meio das mesmas soluções nas mesmas concentrações do trabalho anterior. Os pesquisadores relataram que as soluções de EDTA e ácido cítrico limparam a smear layer das paredes do canal radicular de forma estatisticamente semelhante entre si e que o EDTA proporcionou a maior remoção de íons cálcio seguido pelo ácido cítrico.

O trabalho de Eldeniz et al. (2005) apresenta resultados divergentes ao do presente estudo. De acordo com os autores o ácido cítrico tem a capacidade de reduzir a microdureza dentinária de maneira muito mais eficiente que a do EDTA. Já o estudo de De-Deus et al. (2006) afirma o contrário, que o EDTA é a melhor solução.

Para a compreensão e explicação das divergências de resultados encontrados na literatura deve-se analisar a concentração e o pH das soluções envolvidas. Eldeniz et al. (2005) utilizaram o ácido cítrico a 19\%, ao passo que no presente estudo a concentração do mesmo ácido foi de $10 \%$. O efeito quelante do ácido cítrico é diretamente proporcional à sua concentração, ou seja, aumentando-se a concentração potencializa-se o efeito desmineralizante (REIS et al., 2008), justificando os achados de Eldeniz et al. (2005). No experimento realizado por De-Deus et al. (2006) apesar da concentração do ácido cítrico ser a mesma do avaliado no presente trabalho, o $\mathrm{pH}$ utilizado por De-Deus encontrava-se próximo ao neutro, enquanto que no presente estudo o ácido cítrico foi aviado com pH 2,04. O pH mais ácido da solução, provavelmente, deve favorecer o efeito desmineralizante. O ácido cítrico $1 \%$ em pH 1,0 remove maior quantidade de íons cálcio da dentina que a mesma solução em pH 7,4 (SOUSA; SILVA, 2005). Dessa forma, se o ácido cítrico utilizado por De-Deus et al. (2006) apresentava um pH maior $(\cong 7,0)$ ao do ácido utilizado neste experimento $(2,04)$ é natural que a solução com $\mathrm{pH}$ mais elevado apresentasse resultados menos eficientes.

Os valores da medida da microdureza referentes ao grupo da quitosana chamam a atenção pelo fato de que a solução mesmo numa concentração bastante baixa $(0,2 \%)$ apresentou efeito redutor semelhante ao do grupo do EDTA $15 \%$ e ácido cítrico $10 \%$. Por razão econômica, se a solução quelante menos concentrada apresenta o mesmo efeito que a mais concentrada, a primeira deve ser preferida. Em complementação, a quitosana apresenta propriedades de biocompatibilidade e atoxidade às células humanas (SENEL et al., 2000; CHATELET et al., 2001; AKNCBAY et al., 2007), o que sugere, 
até o momento, sua aplicação clínica. Este trabalho inicial sobre o efeito quelante dessa substância abre novas perspectivas de estudos no sentido de conhecer seu mecanismo de ação sobre a dentina e o esmalte dental; o efeito dessa solução sobre a smear layer; identificar a concentração mais adequada para sua utilização na endodontia; quantificar a concentração de íons cálcio removidos do canal radicular; avaliar o grau de rugosidade provocado por essa solução sobre as paredes dentinárias. 


\section{CONCLUSÃO}

Com base na metodologia empregada e na análise dos resultados obtidos, podese concluir que:

1- As soluções de quitosana 0,2\%, EDTA $15 \%$ e ácido cítrico $10 \%$ apresentam capacidade de redução da microdureza da dentina radicular de forma semelhante entre si. 


\section{REFERÊNCIAS BIBLIOGRÁFICAS}

AKNCBAY, H.; SENEL, S.; AY, Z. Y. Application of chitosan gel in the treatment of chronic periodontitis. J Biomed Mater Res B Appl Biomater., v. 80, n. 2, p. 290-296, 2007.

ANDO F. A study on chemical preparation in endodontic therapy. Part II. Various properties of EDTA, phenolsulfonic acid and citric acid. Aichi Gakuin J Dent Sci. (Japanese), v. 23, p. 455-466, 1985.

ARI, H.; ERDEMIR, A.; BELLI, S. Evaluation of the effect of endodontic irrigation solutions on the microhardness and the roughness of root canal dentin. J. Endod., v. 30, n. 11, p. 792-795, 2004.

BURROW, M. F.; TAKAKURA, H.; NAKAJIMA, M.; INAI, N.; TAGAMI, J.; TAKATSU, T. The influence of age and depth on dentine bonding. Dental Materials, v. 10, n. 2, p. 241-246, 1994.

ÇALT, S.; SERPER, A. Time dependent effects of EDTA on dentin structures. J. Endod., v. 28, n. 1, p. 17-19, 2002.

CHATELET, C., DAMOUR, O., DOMARD, A. Influence of the degree of acetylation on some biological properties of chitosan films. Biomaterials, V. 22, P. 261-268, 2001.

CRUZ-FILHO, A. M.; PAUlA, E. A.; PÉCORA, J. D.; SOUSA-NETO, M. D. Effect of different EGTA concentrations on dentin microhardness. Braz. Dent. J., v. 13, n. 3, p. 188-190, 2002.

CRUZ-FILHO, A. M.; SILVA, R. G.; PÉCORA, J. D. Accion Del EDTAC em La microdureza de La dentina radicular em diferentes tiempos de aplicación. Rev. Odont. Federal Latino Americana (FOLA), v. 2, n. 2, p. 82-90, 1996. 
CRUZ-FILHO, A. M.; SOUSA-NETO, M. D.; SAQUY, P. C.; PÉCORA, J. D. Evaluation of the effect of EDTAC, CDTA, and EGTA on radicular dentin microhardness. J. Endod., v. 27, n. 3, p. 183-184, 2001.

CRUZ-FILHO, A. M.; SOUSA-NETO, M. D.; SAVIOLI, R. N.; SILVA, R. G.; VANSAN, L. P.; PECORA, J. D. Effect of chelating solutions on the microhardness of root canal lumen dentin. J. Endod., v. 37, n. 3, p. 358-362, 2011.

DE-DEUS, G.; PACIORNIK, S.; MAURICIO, M. H. P. Evaluation of the EDTA, EDTAC and citric acid on the microhardness of root dentine. Int. Endod. J., v. 39, n. 1, p. 401-407, 2006.

DE-DEUS, G.; REIS, C.; FIDEL, S.; FIDEL, R. A. S.; PACIORNIK, S. Dentine demineralization when subjected to BioPure MTAD: a longitudinal and quantitative assessment. J. Endod., v. 33, n. 11, p. 1364-1368, 2007.

DE-DEUS, G.; REIS, C.; FIDEL, S.; FIDEL, R. A. S.; PACIORNIK, S. Longitudinal and quantitative evaluation of dentin demineralization when subjected to EDTA, EDTAC and citric acid: a co-site digital optical microscopy study. Oral Surg. Oral Med. Oral Pathol. Oral Radiol. Endod., v. 105, n. 3, p. 391-397, 2008a.

DE-DEUS, G.; REIS, C.; FIDEL, S.; FIDEL, R. A. S.; PACIORNIK, S. Dentine demineralization when subjected to EDTA with or without various wetting agents: a cosite digital optical microscopy study. Int. Endod. J., v. 41, n. 4, p. 279-287, 2008b.

DE-DEUS, G.; ZEHNDER, M.; REIS, C.; FIDEL, S.; FIDEL, R. A. S.; GALAN Jr, J.; PACIORNIK, S. Longitudinal co-site optical microscopy study on the chelating ability of etidronate and EDTA using a comparative single-tooth model. J. Endod., v. 34, n. 1, p. 71-75, 2008c.

ELDENIZ, A. U.; ERDEMIR, A.; BELLI, S. Effect of EDTA and citric acid solutions on the microhardness and the roughness of human root canal dentin. J. Endod., v. 31, n. 2, p. 107-110, 2005.

FAIRBANKS, D. C. O.; CRUZ-FILHO, A. M.; FIDEL, R. A. S.; PÉCORA, J. D. Avaliação da ação de 3 soluções auxiliares quelantes na microdureza da dentina radicular. Rev. Bras. Odont., v. 54, n. 4, p.232-235, 1997.

FUENTES, V.; TOLEDANO, M.; OSORIO, R.; CARVALHO, R. M. Microhardness of superficial and deep sound human dentin. J. Biomed. Mater. Res. A., v. 66, n. 4, p. 850- 853, 2003.

HAZNEDAROGLU, F. Efficacy of various concentrations of citric acid at different $\mathrm{pH}$ values for smear layer removal. Oral Surg. Oral Med. Oral Pathol. Oral Radiol. Endod., v. 96, n.3, p. 340-344, 2003.

HÜLSMANN, M.; HECKENDORFF, M.; LENNON, A. Chelating agents in root canal treatment: mode of action and indications for their use. Int. Endod. J., v. 36, n. 12, p. 810-830, 2003. 
KURITA, K. Chemistry and application of chitin and chitosan. Polymer Degradation and Stability, v. 59, n.1-3, p. 117-120, 1998.

LOTTANTI, S.; GAUTSCHI, H.; SENER, B; ZEHNDER, M. Effects of ethylenediaminetetraacetic, etidronic and peracetic acid irrigation on human root dentine and the smear layer. Int. Endod. J., v. 42, n. 4, p. 335-343, 2009.

MACHADO-SILVEIRO, L. F.; GONZÁLEZ-LÓPEZ, S.; GONZÁLEZ-RODRÍGUEZ, M. P. Decalcification of root canal dentine by citric acid, EDTA and sodium citrate. Int. Endod. J., v. 37, n. 6, p. 365-369, 2004.

MARQUES, A. A. F.; MARCHESAN, M. A.; SOUSA-FILHO, C. B.; SILVA-SOUSA, Y. T. C.; SOUSA-NETO, M. D.; CRUZ-FILHO, A. M. Smear layer removal and chelated calcium ion quantification of three irrigating solutions. Braz. Dent. J., v. 17, n. 4, p. 306-309, 2006.

NYGAARD-ØSTBY, B. Chelation in root canal therapy: ethylenediaminetetraacetic acid for cleansing and widening of root canals. Odontologisk Tidskrift, v. 65, p. 3-11, 1957.

OLIVEIRA, L. D.; CARVALHO, C. A. T.; NUNES, W.; VALERA, M. C.; CAMARGO, C. H. R.; JORGE, A. O. C. Effects of chlorhexidine and sodium hypochlorite on the microhardness of root canal dentin. Oral Surg. Oral Med. Oral Pathol. Oral Radiol. Endod., v. 104, n. 4, p. e125-e128, 2007.

PANIGHI, M.; G'SELL, C. Influence of calcium concentration on the dentine wettability by an adhesive. J Biomed Mater Res., v. 26, p. 1081-1089, 1992.

PAPAGIANNI, M. Advances in citric acid fermentation by Aspergillus niger: Biochemical aspects, membrane transport and modeling. Biotechology Advances, 2007.

PASHLEY, D.; OKABE, A.; PARHAM, P. The relationship between dentine microhardness and tubule density. Endod. Dental Traum., v. 1, n. 5, p. 176-179, 1985.

PATIL, C. R.; UPPIN, V. Effect of endodontic irrigating solution on the microhardness nd roughness of root canal dentin: an in vitro study. Indian J. Dent. Res., v. 22, n. 1, p. 22-27, 2011.

PÉREZ-HEREDIA, M.; FERRER-LUQUE, C. M.; GONZÁLEZ-RODRÍGUEZ, M. P. The effectiveness of different acid irrigating solutions in root canal cleaning after hand and rotary instrumentation. J. Endod., v. 32, n. 10, p. 993-997, 2006.

PÉREZ-HEREDIA, M.; FERRER-LUQUE, C. M.; GONZÁLEZ-RODRÍGUEZ, M. P.; MARTÍN-PEINADO, F. J.; GONZÁLEZ-LOPEZ, S. Descalcifying effect of $15 \%$ EDTA, $15 \%$ citric acid, 5\% phosphoric acid and 2,5\% sodium hypochlorite on root canal dentine. Int. Endod. J., v. 41, n. 5, p. 418-423, 2008.

PRADO, M.; GUSMAN, H.; GOMES, B. P. F. A.; SIMÃO, R. A. Scanning Electron Microscopic Investigation of the Effectiveness of Phosphoric Acid in Smear Layer 
Removal When Compared with EDTA and Citric Acid. J. Endod., v. 37, n. 2, p. 255$258,2011$.

QING, Y.; AKITA, Y.; KAWANO, S.; KAWAZU, S.; YOSHIDA, T.; SEKINE, I. Cleaning efficacy and dentin micro-hardness after root canal irrigation with a strong acid electrolytic water. J. Endod., v. 32, n. 11, p. 1102-1106, 2006.

REIS, C.; DE-DEUS, G.; LEAL, F.; AZEVEDO, E.; COUTINHO-FILHO, T.; PACIORNIK, S. Strong effect on dentin after the use of high concentrations of citric acid: na assessment with co-site optical microscopy and ESEM. Dent. Mater., v. 24, n. 12, p. 1608-1615, 2008.

SALAMA, F. S.; ABDELMEGID, F. Y. Six percent citric acid better than hydrogen peroxide in removing smear layer: an in vitro pilot study. Pediatr. Dent., v. 16, n. 6, p. 424-426, 1994.

SALEH, A. A.; ETTMAN, W. M. Effect of endodontic irrigation solutions on microhardness of root canal dentine. J. Dent., v. 27, n. 1, p. 43-46, 1999.

SAYIN, T. C.; SERPER, A.; CEHRELI, Z. C.; OTLU, H. G. The effect of EDTA, EGTA, EDTAC and tetracycline- $\mathrm{HCl}$ with and without subsequent $\mathrm{NaOCl}$ treatment on the microhardness of root canal dentin. Oral. Surg. Oral Med. Oral Pathol. Oral Radiol. Endod. v. 104, n. 3, p. 418-424, 2007.

SCELZA, M. F.; TEIXEIRA, A. M.; SCELZA, P. Decalcifying effect of EDTA-T, 10\% citric acid, and $17 \%$ EDTA on root canal dentin. Oral. Surg. Oral Med. Oral Pathol. Oral Radiol. Endod., v. 95, n. 2, p. 234-236, 2003.

SENEL, S.; KAS, H. S.; SQUIER, C. A. Application of chitosan in dental drug delivery and therapy. In: Muzzarelli RAA, editor. Chitosan Per os: From Dietary Supplement to Drug Carrier. Italy: Atec, Grottammare; p. 241-256, 2000.

SLUTZKY-GOLDBERG, I.; MAREE, M.; LIBERMAN, R.; HELING, I. Effect of sodium hypochlorite on dentin microhardness. J. Endod., v. 30, n. 12, p. 880-882, 2004.

SOUSA, S. M. G.; SILVA, T. L. Demineralization effect of EDTA, EGTA, CDTA and citric acid on root dentin: a comparative study. Braz. Oral Res., v. 19, n. 3, p. 188-192, 2005 .

SPANÓ, J. C. E.; SILVA, R. G.; GUEDES, D. F. C.; SOUSA-NETO, M. D.; ESTRELA, C.; PÉCORA, J. D. Atomic absorption spectrometry and scanning electron microscopy evaluation of concentration of calcium ions and smear layer removal with root canal chelators. J. Endod., v. 35, n. 5, p. 727-730, 2009.

URAGAMI, T.; YAMAMOTO, S.; MIYATA, T. Dehydration from alcohols by polyion complex cross-linked chitosan composite membranes during evapomeation. Biomacromolecules, v. 4, n. 1, p. 137-144, 2003. 
VOGEL, A. I. Análise química quantitativa. 6 ed., LTC- livros técnicos e científicos editora SA, Rio de Janeiro, RJ, p. 26-27, 2002. 
ANEXOS 


\section{Anexo 1}

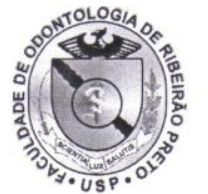

\section{UNIVERSIDADE DE SÃO PAULO}

Faculdade de Odontologia de Ribeirão Preto

Comitê de Ética em Pesquisa

Of.ATAC.CEP/16211/FORP-USP/26.04.2011

CHLS/fdc

Ref. processo $n .^{\circ} \underline{2011.1 .370 .58 .7}$

Senhora Pesquisadora:

CAAE $n .^{\circ} 0023 \cdot 0.138 .000-11$

Informamos que o Comitê de Ética em Pesquisa, em sua 119. ${ }^{a}$ Sessão, realizada em 14 de abril de 2011, aprovou o desenvolvimento do projeto de pesquisa envolvendo seres humanos, intitulado "Avaliação do efeito de diferentes agentes quelantes e desmineralizantes sobre a microdureza da dentina radicular".

$\mathrm{Na}$ oportunidade, lembramos da necessidade de ser entregue, na secretaria do CEP, O Relatório Final em 14/04/2012, com o respectivo formulário preenchido pelo pesquisador responsável.

Lembramos ainda que, quando da submissão do relatório a este Comitê, quaisquer inclusões ou modificações no projeto original deverão ser comunicadas e justificadas ao CEP, através do formulário supracitado.

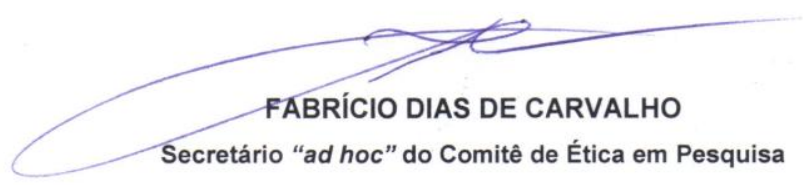

IIm. ${ }^{\text {a }} \mathrm{Sr}{ }^{\text {a }}$

PG. JOSILAINE AMARAL PIMENTA (Prof. Dr. Antônio Miranda da Cruz Filho)

Departamento de Odontologia Restauradora

desta Faculdade 
Anexo 2

Dados originais com as respectivas médias

\begin{tabular}{|c|c|c|c|c|}
\hline \multirow[b]{2}{*}{ Dentes } & \multicolumn{4}{|c|}{ Soluções } \\
\hline & EDTA & Ac. Cítrico & Quitosana & Controle \\
\hline \multirow{4}{*}{01} & 22,2 & 18,7 & 28,6 & 30,7 \\
\hline & 23,3 & 19,5 & 26,9 & 36,8 \\
\hline & 23,4 & 20,0 & 28,0 & 33,8 \\
\hline & 22,9 & 19,4 & 27,8 & 33,7 \\
\hline \multirow{4}{*}{02} & 14,6 & 18,9 & 29,8 & 32,3 \\
\hline & 16,2 & 20,2 & 27,8 & 34,4 \\
\hline & 15,4 & 19,4 & 29,8 & 36,6 \\
\hline & 15,4 & 19,5 & 29,1 & 34,4 \\
\hline \multirow{4}{*}{$\mathbf{0 3}$} & 21,7 & 27,4 & 29,2 & 41,3 \\
\hline & 19,5 & 23,1 & 31,9 & 40,6 \\
\hline & 17,4 & 25,0 & 30,5 & 43,1 \\
\hline & 19,5 & 25,1 & 30,5 & 41,6 \\
\hline \multirow{4}{*}{04} & 24,5 & 29,0 & 28,4 & 39,6 \\
\hline & 26,0 & 27,4 & 29,2 & 40,6 \\
\hline & 26,9 & 28,0 & 30,5 & 40,6 \\
\hline & 25,8 & 28,1 & 29,3 & 40,2 \\
\hline \multirow{4}{*}{05} & 33,8 & 18,2 & 31,9 & 40,0 \\
\hline & 34,6 & 16,4 & 34,3 & 43,5 \\
\hline & 34,1 & 14,3 & 35,1 & 44,6 \\
\hline & 34,1 & 16,3 & 33,7 & 42,7 \\
\hline \multirow{4}{*}{06} & 33,8 & 20,8 & 22,9 & 35,7 \\
\hline & 36,0 & 16,1 & 23,1 & 34,7 \\
\hline & 31,4 & 17,7 & 22,7 & 33,8 \\
\hline & 33,7 & 18,2 & 22,9 & 34,7 \\
\hline \multirow{4}{*}{07} & 23,7 & 17,9 & 22,0 & 44,6 \\
\hline & 27,3 & 16,8 & 23,6 & 44,2 \\
\hline & 25,5 & 18,3 & 20,5 & 42,0 \\
\hline & 25,5 & 17,6 & 22,0 & 43,6 \\
\hline \multirow{4}{*}{08} & 15,6 & 14,1 & 14,6 & 45,0 \\
\hline & 16,2 & 13,0 & 14,1 & 46,6 \\
\hline & 17,4 & 12,0 & 14,3 & 43,5 \\
\hline & 16,4 & 13,0 & 14,3 & 45,0 \\
\hline \multirow{4}{*}{09} & 19,2 & 17,2 & 20,0 & 18,7 \\
\hline & 17,7 & 15,1 & 21,5 & 17,8 \\
\hline & 20,2 & 14,4 & 20,2 & 16,9 \\
\hline & 19,0 & 15,5 & 20,5 & 17,8 \\
\hline \multirow{4}{*}{10} & 32,2 & 21,1 & 15,1 & 35,4 \\
\hline & 31,2 & 20,0 & 15,9 & 36,6 \\
\hline & 33,3 & 21,0 & 16,3 & 35,1 \\
\hline & 32,2 & 20,7 & 15,7 & 35,7 \\
\hline
\end{tabular}

